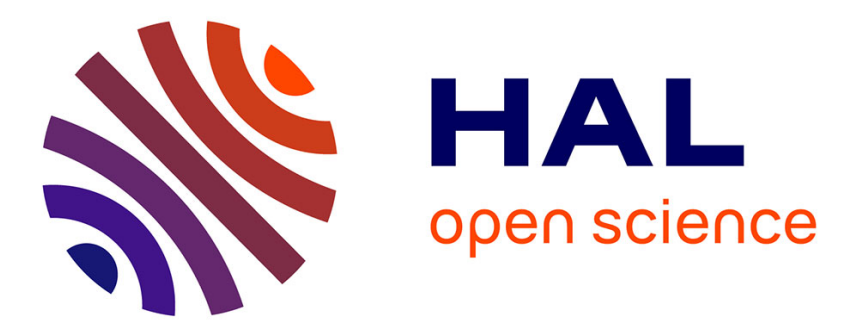

\title{
Interplay of the adsorption of light and heavy paraffins in hydroisomerization over $\mathrm{H}$-beta zeolite
}

\author{
Pedro Mendes, Céline Chizallet, Javier Perez-Pellitero, Pascal Raybaud, João
} Nuno Silva, M. Filipa Ribeiro, Antoine Daudin, Christophe Bouchy

\section{- To cite this version:}

Pedro Mendes, Céline Chizallet, Javier Perez-Pellitero, Pascal Raybaud, João Nuno Silva, et al.. Interplay of the adsorption of light and heavy paraffins in hydroisomerization over H-beta zeolite. Catalysis Science \& Technology, 2019, 9 (19), pp.5368-5382. 10.1039/C9CY00788A . hal-02414552

\section{HAL Id: hal-02414552 \\ https://hal-ifp.archives-ouvertes.fr/hal-02414552}

Submitted on 16 Dec 2019

HAL is a multi-disciplinary open access archive for the deposit and dissemination of scientific research documents, whether they are published or not. The documents may come from teaching and research institutions in France or abroad, or from public or private research centers.
L'archive ouverte pluridisciplinaire HAL, est destinée au dépôt et à la diffusion de documents scientifiques de niveau recherche, publiés ou non, émanant des établissements d'enseignement et de recherche français ou étrangers, des laboratoires publics ou privés. 


\section{Interplay of the adsorption of light and heavy}

\section{paraffins in hydroisomerization}

\section{over H-Beta zeolite}

4 Pedro S. F. Mendes ${ }^{\mathrm{a}, \mathrm{b}^{*}}$, Céline Chizallet, ${ }^{\mathrm{b}}$ Javier Pérez-Pellitero, ${ }^{\mathrm{b}}$ Pascal Raybaud, ${ }^{\mathrm{b}}$ João

5 M. Silva, ${ }^{\mathrm{a}, \mathrm{c}}$ M. Filipa Ribeiro, ${ }^{\mathrm{a}}$ Antoine Daudin, ${ }^{\mathrm{b}}$ Christophe Bouchy ${ }^{\mathrm{b}}$ *

$6 \quad{ }^{a}$ Centro de Química Estrutural, Instituto Superior Técnico, Universidade de Lisboa, Av.

$7 \quad$ Rovisco Pais, 1049-001 Lisboa, Portugal

$8{ }^{b}$ IFP Energies nouvelles, Rond-point de l'échangeur de Solaize, BP 3, 69360 Solaize,

$9 \quad$ France

${ }^{c}$ ADEQ-ISEL, Instituto Superior de Engenharia de Lisboa, Instituto Politécnico de

Lisboa, R. Cons. Emídio Navarro, 1959-007 Lisboa, Portugal

Academic studies

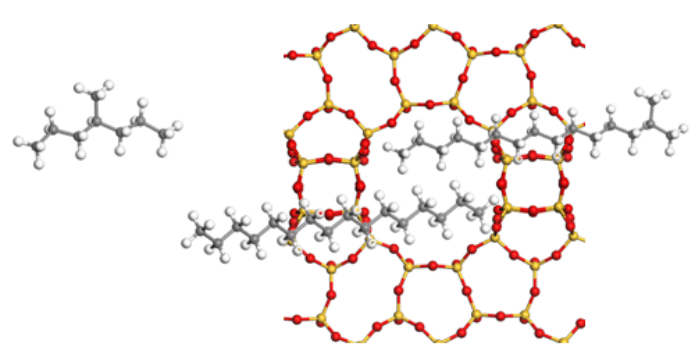

Pressure

Isomers yield
Industrial conditions

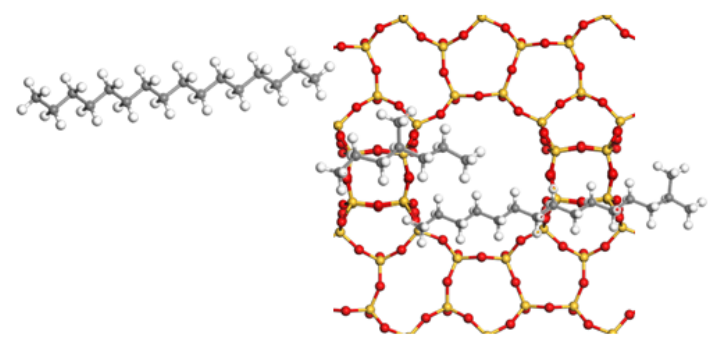

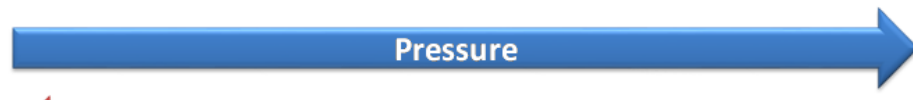

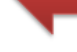

Hydroisomerization: controlling selectivity by tuning the $\mathrm{Pt} /$ zeolite properties 


\section{Abstract}

2 The effect of pressure on the activity and selectivity of well-balanced $\mathrm{Pt} / \mathrm{H}-\mathrm{Beta}$

3 bifunctional catalysts in $n$-hexadecane $\left(n-C_{16}\right)$ hydroisomerization was studied. The

4 turnover frequency per Brønsted acid site of the catalyst decreased when increasing

5 pressure due to the lower concentration in olefins at equilibrium, in line with the

6 classical bifunctional mechanism. Conversely, when increasing the total pressure, the

$7 \quad \mathrm{C}_{16}$ isomer yield unexpectedly decreased in contradiction with pure kinetic/

8 thermodynamic effect of olefin pressure on the reaction rates. Thanks to Grand

9 Canonical Monte Carlo (GCMC) calculations, non-idealities in adsorption behavior in

10 the zeolite micropores were revealed when considering a representative reaction

11 medium. Via mechanistic kinetic simulations combined with GCMC simulations for the

12 relevant intermediates concentrations, the pressure effect on catalyst selectivity is

13 proposed to be due to the interplay between the (light) cracked products and the (heavy)

14 hexadecanes in the pores of Beta zeolite which leads to a pressure-dependency on the 15 adsorption behavior. 


\section{$1 \quad 1$ Introduction}

2 Bifunctional catalysts comprising acid and hydrogenation-dehydrogenation

3 functions are of utmost important in industrial hydroconversion processes. The use of

4 such catalysts enables the conversion of either conventional or sustainable carbon

5 sources into liquid fuels. ${ }^{1-6}$ With the liquid fuels for transportation accounting for $30 \%$

6 of the worldwide energy consumption and the most recent reports foreseeing an increase

7 of $20 \%$ in liquid fuels demand by $2040,{ }^{7}$ improved atom economy can save

8 considerable amounts of carbon resources for other applications. Enhancing the

9 selectivity of industrial hydroconversion catalysts is, hence, a timely issue.

Focusing on the hydroisomerization of long chain $n$-paraffins, the bifunctional catalyst typically consists of a noble metal finely dispersed over a zeolite (usually mixed with alumina). ${ }^{8}$ For a given set of operating conditions, the activity and selectivity of such catalysts are controlled by i) the ratio of metal to Brønsted acid sites, ${ }^{8-13}$ ii) the distance between those sites, ${ }^{8,14-17}$ and iii) the topology and pore structure of the zeolite. ${ }^{11,18-22}$ Ensuring optimal ratio and intimacy between metal and acid sites (socalled "well-balanced catalyst") results in maximal activity and selectivity towards feed isomers, as well as minimal secondary cracking, for a given zeolite. The choice of the adequate zeolite depends on acid-basic properties and on its pore architecture combining micro and mesopores. ${ }^{6,23,24}$ The pores of the zeolite can act either as a

20 molecular sieve, i.e. by excluding molecules based on its shape and size,$^{25-28}$ or as solid

21 solvents, i.e. by interacting with confined molecules resulting in the (physical)

22 adsorption of such molecules. ${ }^{29-33}$ Depending on the zeolite structure and composition as well as on the size and nature of the molecule at stake, confinement effects can result 
1 in selective adsorption, enhanced/restricted diffusivity or even (transition-state or 2 product) shape selectivity. ${ }^{31,34-37}$ 7 H-Beta-based catalysts, ${ }^{18,20,38-45}$ as well as over some medium-pore frameworks. ${ }^{18,46-48}$

8 Due to their recurrently greater TOF per protonic site compared to $\mathrm{Pt} / \mathrm{H}-\mathrm{USY}$ in the 9 hydroconversion of $n$-paraffins, $\mathrm{Pt} / \mathrm{H}$-Beta catalysts are particularly interesting. 10 Noticeably, this behavior has been observed regardless of the considered $\mathrm{Si} / \mathrm{Al}$ ratios.

A large diversity of catalytic performances in n-paraffins hydroisomerization has been reported depending on the zeolite structure. ${ }^{18,19}$ Despite the acceptance that $\mathrm{H}-$ USY (protonic Ultra-Stable Y, FAU framework) zeolite has gained in industrial hydroconversion processes, ${ }^{1}$ literature reports have highlighted promising results over $38,49,50$ On the contrary, there is no consensus with respect to the isomerization selectivity. Some authors revealed a prominent isomerization behavior of H-Beta zeolite 20,42,43,50-52 while others disclosed high cracking yields even for intermediate levels of conversion ${ }^{38,53}$ leading to significant overcracking, as compared to e.g. H-USY.

On the other way around, for a given catalyst formulation, the operating conditions can also play a role in the catalyst performance. Whereas the typical range of industrial reaction temperatures can be easily achieved in laboratory conditions, the same is not valid for total pressure and hydrogen to hydrocarbon molar ratios. Due to safety reasons and growing costs, most of the laboratory-scale tests are performed at much lower total pressures than those industrially relevant. The latter ones can go from as low as 3.5 MPa in the hydroisomerization of Fischer-Tropsch (FT) waxes ${ }^{4}$ to as high as $20 \mathrm{MPa}$ in the hydrocracking of vacuum gas oils (VGOs). ${ }^{1}$ In the same way, high hydrogen to hydrocarbon molar ratios $\left(\mathrm{H}_{2} / \mathrm{HC}\right)$, usually above 20 and often above 100 , are most of the times applied in academic studies to ensure pure gas-phase operation..$^{20,43,50,53}$ In 
1 industry, the typical $\mathrm{H}_{2} / \mathrm{HC}$ volumetric ratios are comprised between 500 and $2000 .{ }^{1}$ For

$2 n$-hexadecane, a molecule that can be present in both FT waxes and light VGOs, a

3 volumetric ratio of 1000 corresponds to a molar ratio of 12 .

As a matter of fact, the effects of operating conditions investigated in the literature

5 have been mostly explained by the modification of the balance between catalytic

6 functions. ${ }^{54-56}$ Sufficiently well-balanced catalysts (i.e. metal to acid sites ratio superior

7 to that required for balance) are, hence, insensitive to small modifications in the

8 operating conditions. This phenomenon is identified by a unique curve of feed isomers

9 yield with conversion. ${ }^{57}$ Nevertheless, variations in the operating conditions,

10 particularly in hydrocarbon partial pressures, affect not only the kinetic intrinsic

11 constants of the surface reactions but also the physisorption of reactants and products in

12 the zeolite. ${ }^{53,58,59}$ As confinement effects increase with pressure, their impact on the reaction rates is expected to be also larger at high partial pressures of hydrocarbons, i.e. in industrially-relevant conditions.

Up to now, studies on hydroconversion have also pointed towards an impact of the confinement effects on the selectivity. ${ }^{53,60,61}$ Recent works are proposing a series of

17 adsorption criteria to screen promising zeolite structures for hydroisomerization ${ }^{62,63}$ or direct relationships between molecular modelled adsorption properties and catalytic results. ${ }^{64,65}$ However, these studies focus on the differences between zeolitic structures and not on the operating conditions. As literature studies are based on hydroconversion tests which are performed at low partial pressures in hydrocarbons, it is of utmost relevance to bridge the gap between those experiments and the industrial conditions and understand the key phenomena. Therefore, the present study focuses on the effect of total pressure on the catalytic performance of zeolite Beta (*BEA), at industrially 
1 relevant hydrocarbon partial pressures. In order to mitigate effects related with metal-

2 acid balance, well-balanced catalysts are employed. For a rational interpretation of the

3 effects observed experimentally, Grand Canonical Monte Carlo (GCMC) simulations of

4 the adsorption properties of reactants and products at reaction conditions are pursued as

5 well, considering the A polymorph of *BEA.

\section{$6 \quad 2$ Materials and Methods}

\section{$7 \quad 2.1 \quad$ Catalyst preparation}

8 Zeolite Beta is composed by two intergrown polymorphs (A and B) stacked in a

9 more or less random fashion generating 3D straight channels with an equivalent 10 minimum pore size of $0.66 \times 0.67 \mathrm{~nm} .{ }^{66}$ The zeolite Beta was supplied by Zeolyst 11 (commercial name CP814E) in ammonium form and was, hence, calcined to obtain the 12 protonic form (H-Beta) using a protocol published elsewhere. ${ }^{67}$

In a preceding work, the Pt loading was varied to study the influence of metal to 14 acid sites ratio on the catalytic performance $\mathrm{Pt} / \mathrm{H}$-Beta catalysts. $^{11}$ Optimal performances in $n$-hexadecane hydroisomerization (at $1.1 \mathrm{MPa}$ and $\mathrm{H}_{2} / n-\mathrm{C}_{16}$ ratio of 12 ) were obtained for surface metal sites to acid sites ratio of 0.02 for $\mathrm{Pt} / \mathrm{H}-\mathrm{Beta}$. Herein, to ensure an optimal metal-acid balance, the Pt loading introduced aimed at achieving a surface metal sites to acid sites ratios $\left(\mathrm{n}_{\mathrm{Pt}}^{\mathrm{S}} / \mathrm{n}_{\mathrm{Al}}\right)$ superior to the referred one. This resulted in Pt loading of 1.0 wt.\%.

The introduction of platinum in the zeolite was performed by incipient wetness impregnation of an aqueous solution of $\left[\mathrm{Pt}\left(\mathrm{NH}_{3}\right)_{4} \mathrm{NO}_{3}\right] \cdot 6 \mathrm{H}_{2} \mathrm{O}$. The concentration of precursor was $44 \mathrm{mmol} \mathrm{L}^{-1}$ resulting in a Pt loading of $1.0 \mathrm{wt} . \%$. The impregnated material was dried overnight at $383 \mathrm{~K}$ and then calcined in an air flow of $4 \mathrm{NL} \mathrm{h}^{-1} \mathrm{~g}^{-1}$. 
1 Three plateaux at 423, 523 and $623 \mathrm{~K}$ over one hour each and a final plateau at $773 \mathrm{~K}$

2 over two hours were performed. A heating rate of $5 \mathrm{~K} \mathrm{~min}^{-1}$ was used. The reduction of

3 platinum was performed in situ before catalytic testing as detailed in section 2.3.

\section{$4 \quad 2.2$ Solids characterization}

5 H-Beta zeolite was characterized by X-Ray Fluorescence (XRF) to determine the

6 total $\mathrm{Si} / \mathrm{Al}$ molar ratio and by ${ }^{27} \mathrm{Al}$ magic angle spinning nuclear magnetic resonance

7 (MAS-NMR) to determine the percentage of framework aluminum $\left(\mathrm{Al}^{\mathrm{IV}}\right)$. The

8 experiments were performed using a Bruker 400 Avance spectrometer equipped with a

$94 \mathrm{~mm}$ CP MAS probe head at RT. The MAS rate was $12 \mathrm{kHz}$ for all experiments. The

$10{ }^{27} \mathrm{Al}$ NMR spectra were obtained using exciting pulses of $1 \mu \mathrm{s}(\pi / 12)$ and relaxation 11 delays of $0.5 \mathrm{~s}$. For the sample employed, the global Si/Al molar ratio was 13 and the percentage of aluminium atoms which were tetracoordinated $\left(\mathrm{Al}^{\mathrm{IV}}\right)$, as determined by

${ }^{27} \mathrm{Al} \mathrm{NMR}$, was $72 \%$. The tetracoordinated aluminium atoms generate negatively charged oxygen atoms in zeolites framework. ${ }^{68}$ Therefore, the concentration of $\mathrm{Al}^{\mathrm{IV}}$ species $\left(840 \mu \mathrm{mol} \mathrm{g} \mathrm{g}^{-1}\right)$ is an estimation of Brønsted acid sites concentration for a zeolite in the protonic form.

ASAP 2010 apparatus. Prior to adsorption, the sample was degassed under vacuum at

$363 \mathrm{~K}\left(\right.$ over $1 \mathrm{~h}$ ) and at $623 \mathrm{~K}\left(\right.$ over $4 \mathrm{~h}$ ). The $t$-plot method ${ }^{69}$ was employed to calculate the microporous volume $\left(\mathrm{V}_{\text {micro }}\right)$ and the external surface area $\left(\mathrm{S}_{\mathrm{ext}}\right)$.

Platinum content of Pt/H-Beta was determined by XRF spectroscopy as well. The metallic dispersion was determined by hydrogen titration of chemisorbed oxygen in an Autochem II 2920 (Micromeritics) apparatus with a thermal conductivity detector. The 
1 samples (200-300 mg) were pre-treated under $\mathrm{H}_{2}\left(30 \mathrm{~mL} \mathrm{~min}^{-1}\right)$ at $473 \mathrm{~K}$ over $30 \mathrm{~min}$

2 and $723 \mathrm{~K}$ over 60 min using a heating rate of $5 \mathrm{~K} \mathrm{~min}^{-1}$, cooled and purged under $\mathrm{Ar}$

$3\left(20 \mathrm{~mL} \mathrm{~min}^{-1}\right)$ over the night. Titration was performed at $308 \mathrm{~K}$ and pulses of $\mathrm{H}_{2}\left(\right.$ or $\left.\mathrm{O}_{2}\right)$

4 were injected every $3 \mathrm{~min}$. The accessible metal $\left(\mathrm{n}_{\mathrm{Pt}}\right)$ was calculated by means of 1.5

$5 \quad \mathrm{H}_{2}$ :Pt stoichiometric coefficient. ${ }^{70,71}$ The platinum dispersion determined was $37 \%$.

6 The properties of the $\mathrm{Pt} / \mathrm{H}$-Beta sample are summarized in Table 1. Further details on

7 the characterization can be found elsewhere. ${ }^{72,73}$ It should be nevertheless noted that,

8 due to the low content of Pt (1 wt.\%) in the zeolite, the influence of Pt introduction on

9 the zeolite properties is expected to be rather limited. This is further supported by the

10 fact Pt clusters are, for this sample, mainly deposed on the external surface of the

11 zeolites. $^{73}$ In a previous work, ${ }^{72}$ the impact of Pt introduction on the BEA zeolite acidity

12 was also assessed. The concentration of Brønsted acid sites decreased by less than 10\%

13 upon Pt introduction and the acid strength did not seemed to be affected. This is also in

14 agreement with the very low metal to acid sites ratio in this catalyst: 0.023 (Table 1).

15 Table 1: Physico-chemical, textural and structural characteristics of $\mathrm{H}$-Beta zeolite and

16 corresponding Pt-containing bifunctional catalyst.

\begin{tabular}{|c|c|c|c|c|c|c|c|c|}
\hline $\begin{array}{l}\text { Pore } \\
\text { aperture } \\
(\mathrm{nm} \times \\
\mathrm{nm})\end{array}$ & $\begin{array}{l}V_{\text {micro }} \\
\left(\mathrm{cm}^{3} / \mathrm{g}\right)\end{array}$ & $\begin{array}{l}S_{\text {ext }} \\
\left(\mathrm{m}^{2} / \mathrm{g}\right)\end{array}$ & $(\mathrm{Si} / \mathrm{Al})_{\text {global }}{ }^{\mathrm{a}}$ & $(\mathrm{Si} / \mathrm{Al})_{\text {framework }}{ }^{b}$ & $\begin{array}{l}\mathrm{n}_{\mathrm{Al}}^{\mathrm{c}} \\
(\mu \mathrm{mol} \\
\left.\mathrm{g}^{-1}\right)\end{array}$ & $\begin{array}{l}\text { Pt loading } \\
\text { (wt.\%) }\end{array}$ & $\begin{array}{l}\text { Pt } \\
\text { dispersion }^{d} \\
(\%)\end{array}$ & $\begin{array}{l}\mathrm{n}_{\mathrm{Pt}} / \mathrm{n}_{\mathrm{Al}} \\
(\mathrm{mol} / \mathrm{mol})\end{array}$ \\
\hline $6.6 \times 6.7$ & 0.17 & 235 & 13 & 18 & 840 & 1.0 & 37 & 0.023 \\
\hline 19 & ${ }^{\mathrm{C}}$ Product of $/$ & concentra & n determined by & $\mathrm{RF}$ to the relative an & it of $(A)^{I V}$ & ) measured by & NMR. & \\
\hline 20 & ${ }^{\mathrm{d}}$ Measured $\mathrm{k}$ & $\mathrm{H}_{2}-\mathrm{O}_{2}$ titr & on. & & & & & \\
\hline
\end{tabular}




\subsection{Catalytic tests}

$\mathrm{Pt} / \mathrm{H}$-Beta was tested in the hydroconversion of $n$-hexadecane at two sets of operating conditions, representing industrial- and academic-relevant conditions. The "high pressure" conditions, 4.1 $\mathrm{MPa}$ and a molar $\mathrm{H}_{2}$ to $\mathrm{n}-\mathrm{C}_{16}$ ratio of 12 , are typical for FT waxes hydroconversion processes (see Introduction). To acquire a wide range of conversion levels, the reaction temperature was ranged from 528 to $538 \mathrm{~K}$ and Weight Hourly Space Velocity (WHSV) from 10 to $100 \mathrm{~h}^{-1}$. To mimic the lower partial pressure of hydrocarbons in most of the scientific studies, the "low pressure" conditions correspond to a lower total of $1.1 \mathrm{MPa}$, but a rather similar molar $\mathrm{H}_{2}$ to $\mathrm{n}-\mathrm{C}_{16}$ ratio of 10, to avoid possible concurrent reactant ratio effects. A constant WHSV value of $2.0 \mathrm{~h}^{-}$ ${ }^{1}$ was employed, the conversion level being thus manipulated by varying the reaction temperature from 453 to $503 \mathrm{~K}$. Before the test, the catalyst powder was pelletized and sieved into pellets of $0.2-0.35 \mathrm{~mm}$ and pre-treated using a $\mathrm{H}_{2}$ flow rate of $4 \mathrm{NL} \mathrm{h}^{-1} \mathrm{~g}^{-1}$ and heated at $5 \mathrm{~K} \mathrm{~min}^{-1}$ to a final reduction temperature of $723 \mathrm{~K}$ for one hour. The absence of transport phenomena was verified according to the criteria reported in literature. ${ }^{74}$ Catalytic performances were calculated by mass balance to the carbon atoms at the outlet of the fixed bed reactor. $\mathrm{n}-\mathrm{C}_{16}$ conversion was calculated as the amount of carbon atoms of the products divided by total amount of carbon atoms. The yield of a given product was calculated as the amount of carbon atoms of that product divided by total amount of carbon atoms. Activity was calculated as the apparent kinetic constant for first-order consumption of $n$-hexadecane per catalyst mass per unit of time. The average turnover frequency per Brønsted sites $\left(\mathrm{TOF}_{\mathrm{Al}}\right)$ was defined as the activity per mole of Brønsted acid site of the zeolite, $\mathrm{Al}^{\mathrm{IV}}$. Deactivation of all samples was negligible at the end of the catalytic tests. 


\section{$1 \quad 2.4$ Grand Canonical Monte Carlo (GCMC) calculations}

2 GCMC simulations combined with a bias scheme for the insertion of the centre of 3 mass of the guest molecules were performed at $538.15 \mathrm{~K}$ to calculate adsorption 4 isotherms and selectivities of both pure hydrocarbons and mixtures in zeolite Beta. The

5 structure was represented by a $3 \times 3 \times 3$ purely siliceous cell of the A polymorph of $*$ BEA 6 (taken from the IZA database) ${ }^{75}$. The simulations were performed using the GIBBS 9.3 7 code. ${ }^{76}$ The adsorbate molecules were described according to the anisotropic united 8 atom (AUA) for hydrocarbons, ${ }^{77}$ while the description of the zeolite was based on a 9 "Kiselev type" potential ${ }^{78}$ where the depth of the potential well was slightly modified 10 in order to better match the experimental adsorption data available for pure linear alkanes (octane and hecadecane) in *BEA and FAU. Generally, the force fields used for the simulation are validated for pure compounds only in fluid phase or in adsorbed phase from their adsorption isotherms. It exists indeed seldom reference data for mixed hydrocarbons. However, the AUA force field is built in such a way to ensure a robust transferability through pseudo-atoms and the use of well-defined mixing rules for the calculation of interaction between pseudo-atoms belonging to different molecules. ${ }^{79}$ In this way, the adsorption isotherms were determined from experimental data according to the model proposed by Denayer et al. ${ }^{80}$ and compared to those obtained from the simulations. 10 million Monte Carlo steps were accumulated for pure compounds, and at least 50 million steps for mixtures. Further details about the model parameters and methodologies are provided in the Supporting Information (SI1). 


\section{Results}

\subsection{Hydroisomerization of $n$-hexadecane at "low" and "high" pressures}

\section{$3 \quad$ 3.1.1 Turnover frequency over protonic sites}

As referred in Section 2.3, the catalyst was tested at two different pressures (1.1 and 4.1 $\mathrm{MPa}$ ) corresponding also to two different ranges of reactions temperatures to cover large conversion ranges. An Arrhenius-type plot for the average turnover frequency $\mathrm{TOF}_{\mathrm{Al}}$ throughout the reactor at 1.1 and $4.1 \mathrm{MPa}$ total pressure is reported in Figure 1. It is worth mentioning that the average turnover frequency was calculated by assuming a first-order kinetics in $n$-hexadecane, which can be deduced for the classical bifunctional mechanism ${ }^{11}$ and has been verified experimentally as well ${ }^{54,56,81,82}$.

According to the Arrhenius plot, the increase in pressure from 1.1 to $4.1 \mathrm{MPa}$ resulted in lower $\mathrm{TOF}_{\mathrm{Al}}$ over $\mathrm{Pt} / \mathrm{H}-\mathrm{Beta}$ catalyst. This detrimental effect of pressure on the activity of well-balanced catalysts has been interpreted in the literature as a reduction on the equilibrium partial pressure of olefins generated by dehydrogenation of paraffins over the metal sites. ${ }^{54,56}$ This trend is in agreement with Le Chatelier principle, as dehydrogenation leads to an increase in the number of molecules. Otherwise, if the dehydrogenation reaction was not thermodynamically limited, augmenting pressure would have increased the dehydrogenation rate due to the increase on paraffin partial pressure, i.e. a kinetic effect. ${ }^{54}$ In this case, the $\mathrm{TOF}_{\mathrm{Al}}$ is expected to increase when the total pressure increases. The detrimental effect of pressure observed here confirmed, hence, the adequate balance between metal and acid sites in the employed catalyst. 


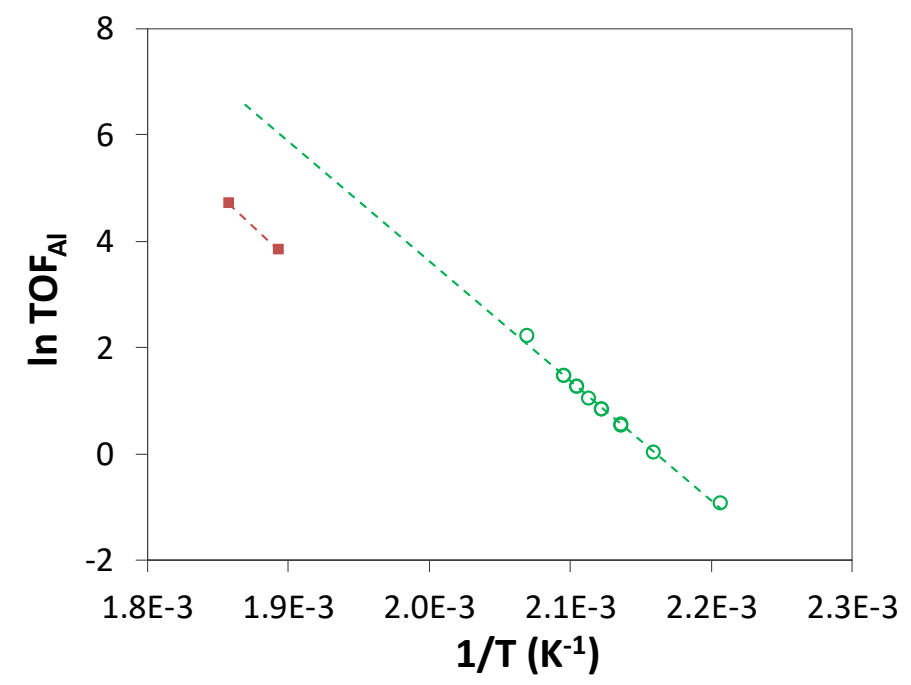

2 Figure 1: Arrhenius plot for hydroconversion turnover frequency over protonic sites $\left(10^{3} \mathrm{~s}^{-1}\right)$

3 for Pt/H-Beta catalyst at $1.1(0)$ and $4.1 \mathrm{MPa}(\square)$ of total pressure. Each point at 4.1 $\mathrm{MPa}$

4 corresponds to the average $\mathrm{TOF}_{\mathrm{Al}}$ obtained using, at least, four different contact times at the

\section{$6 \quad 3.1 .2 \quad$ Product yield and selectivity}

7

8

The yield of $\mathrm{C}_{16}$ isomers was plotted as function of conversion for each set of operating conditions (Figure 2). There is a striking difference in the yields of $\mathrm{i}-\mathrm{C}_{16}$ which can be reached at low and high pressures. More specifically, the maximal yield of $\mathrm{C}_{16}$ isomers decreased expressively (from 67 to $46 \%$ ) with increasing total pressure (from 1.1 $\mathrm{MPa}$ to $4.1 \mathrm{MPa}$ ). According to the literature, high pressures favour the balance of the acidic function by the HDH one ${ }^{53,54}$ leading hence to higher feed isomers yields, ${ }^{83}$ for poor-balanced catalysts. For sufficiently well-balanced (i.e. metal to acid sites ratio superior to that required for balance), variations of the operating conditions will not modify the balance between the catalytic functions and a unique feed isomer yield curve is observed regardless of the operating conditions. ${ }^{54,57}$ In our case, the balance between the catalytic functions has been ensured by optimization of Pt loading. Furthermore, the observation of unique isomer yield curves at different temperatures 
1 (SI2) as well as the decrease of turnover frequency with increasing pressure (previous

2 section) provided robust additional evidence for the optimal balance of the catalyst

3 regardless of the operating conditions. The pressure effect observed herein is therefore

4 not in line with any of the previous observations in literature.

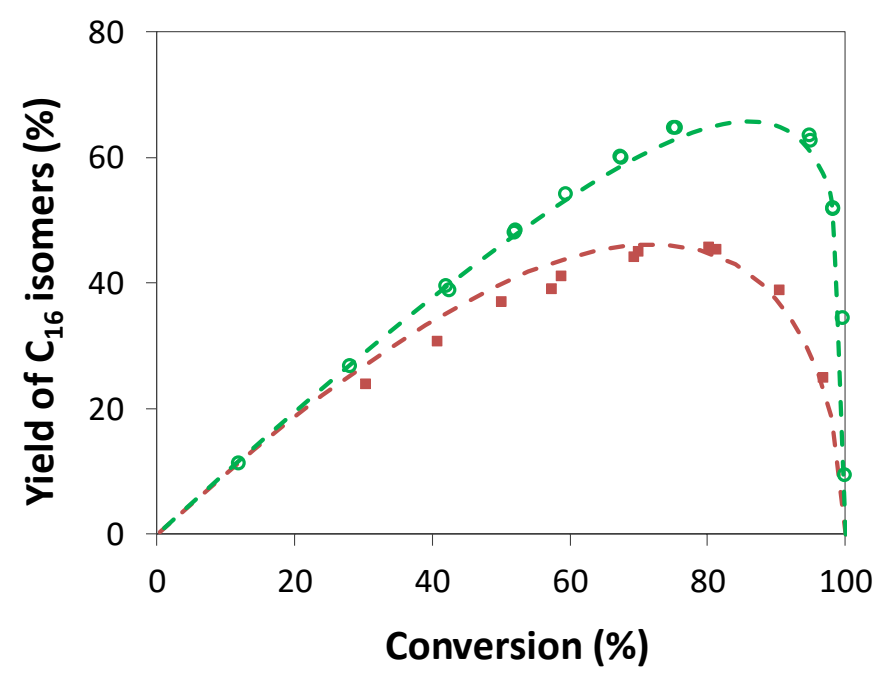

$6 \quad$ Figure 2: Yield of feed isomers as function of n-hexadecane conversion for $\mathrm{Pt} / \mathrm{H}$-Beta catalyst at $1.1(\mathrm{O})$ and 4.1 MPa ( $\square$ ) of total pressure. Dashed lines correspond to kinetic model (Eq. 1 of the main text).

Further insight into the effect of pressure can be grasped by analysing the product selectivity, in terms of lumped products, i.e. monobranched isomers of hexadecane (MB), multibranched isomers of hexadecane (MTB), and cracked products (CP). At 1.1 MPa (Figure 3a), MB were the main products until $50 \%$ of conversion. Afterwards, MTB products were predominant reaching a maximum at ca. $80 \%$ conversion. CP increased steadily with conversion and were negligible for conversions lower than $40 \%$. This corresponds to a predominantly consecutive mechanism. At 4.1 MPa (Figure 3b), the trends are qualitatively the same, but the main products were MTB over a broad conversion range being only surpassed by the cracking products for 
1 conversions above $80 \%$. The apparent reaction scheme was thus predominantly

2 consecutive over both pressures. Conversely, the increased pressure led, on the one

3 hand, to a remarkable reduction in the selectivity towards monobranched and, in a lower

4 extent, multibranched $\mathrm{C}_{16}$ isomers over the whole range of experimental conversions,

5 and, on the other hand, to an increased selectivity towards $\mathrm{CP}$. The lower yield of $\mathrm{C}_{16}$

6 isomers revealed in Figure 2 is a direct consequence of the important increase in $\mathrm{CP}$

$7 \quad$ with increasing pressure.
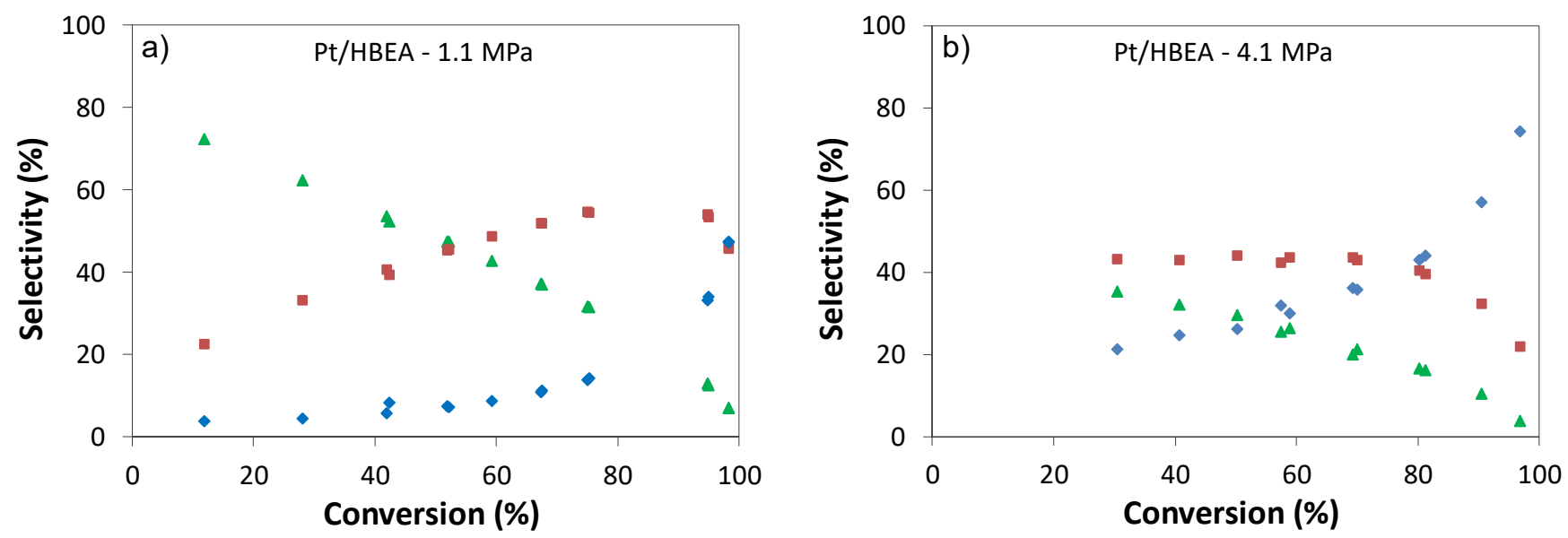

Figure 3: Selectivity in monobranched $(\Delta)$ and multibranched $(\boldsymbol{\nabla}) \mathrm{C}_{16}$ isomers,

9 and cracking $(\diamond)$ products as function of conversion at a) 1.1 and b) 4.1 MPa total pressure.

Lumping the monobranched and multibranched isomers into a single product,

11 the apparent scheme for hydrocracking boils down to two consecutive reactions:

12 isomerization followed by cracking (Scheme 1). For a series of two consecutive first-

13 order reactions with no variation on the total number of moles, the outlet flowrate $(\mathrm{F})$

14 profiles can be derived analytically and, thereby, the yield in the primary product as a

15 function of the reactant conversion (Eq. 1) ${ }^{84}$ - see SI3 for more details. More

16 interestingly, the ratio of the (apparent) kinetic constants (k) can be estimated directly

17 from the $\mathrm{C}_{16}$ isomer yield $\left(\mathrm{Y}_{\mathrm{i}-\mathrm{C} 16}\right)$ vs. conversion curve $(\mathrm{x})$. 


$$
\begin{array}{cc}
\mathrm{n}-\mathrm{C}_{16} \stackrel{\mathbf{r}_{\text {isom }}}{\longrightarrow} \mathrm{i}-\mathrm{C}_{16} \stackrel{\mathbf{r}_{\text {crack }}}{\longrightarrow} \mathrm{CP} & \text { Scheme 1 } \\
Y_{i-C_{16}}=\frac{F_{i-C_{16}}}{F_{C_{n-C_{16}}}^{0}}=\frac{1}{k_{\text {crack } / k_{\text {isom }}^{\text {app }}-1}^{\longrightarrow}-1}\left[\begin{array}{cr}
k_{\text {crack }}^{\text {app }} / k_{\text {isom }}^{\text {app }} \\
\end{array}\right] & \text { Equation 1 }
\end{array}
$$

2 sum of weighed squared residuals, as detailed in SI3. The simulated curve (based on the

The kinetic constants ratio was estimated for both pressures by minimizing the

estimated ratios) is compared with experimental data in Figure 2. The simulations showed a very good agreement with experimental points, despite the simple nature of the kinetic model (vide Fig. S4 for parity plots). The consecutive nature of the hydroconversion over $\mathrm{Pt} / \mathrm{H}$-Beta at both pressures was, hence, confirmed. In literature, consecutive apparent reaction schemes have been frequently associated with wellbalanced catalysts, as a fast rate of hydrogenation/de-hydrogenation reactions diminishes the number of consecutive steps over acid sites. ${ }^{9,11}$ In contrast, in poorlybalanced catalysts, the number of consecutive steps over the acid sites is large. Therefore, not only monobranched but also multibranched and, ultimately, cracked products can appear as primary products. Such situation corresponds to a parallel reaction scheme. This observation consubstantiated, once again, the adequate balance between catalytic functions in the explored operating conditions.

The values of $\mathrm{k}_{\text {crack }}^{\mathrm{app}} / \mathrm{k}^{\mathrm{app}}$ isom estimated were 0.61 and 0.21 at 4.1 and $1.1 \mathrm{MPa}$, respectively. This means that increasing the pressure from 1.1 to $4.1 \mathrm{MPa}$ tripled the apparent cracking kinetic constant relatively to that of isomerization. Such relative increase in the apparent rate of cracking matches the lower yield of $\mathrm{C}_{16}$ isomers observed experimentally at higher pressure. In short, the kinetic model based on the apparent reaction scheme (Scheme 1) represented adequately, both quantitatively and 
1 qualitatively, the evolution of $\mathrm{C}_{16}$ isomers yield with conversion. Considering the

2 bifunctional mechanism, the increase, with pressure, in the apparent rate of cracking

3 compared to the isomerization one is in contradiction with the expected unique isomer

4 yield curve optimal metal-acid balance. This latter was corroborated, as already

5 referred, via the decreasing turnover frequency with pressure and the unique isomer

6 yield curve with temperature.

Concerning possible diffusion limitations, an increase in pressure would lead to a faster diffusion of the molecules, due to a higher mass transfer driving force. Moreover, it has been reported that the sorbate intracristalline effective diffusivity in a zeolite tends to increase with the sorbate concentration inside the zeolite ${ }^{85}$. Higher sorbate concentration is expected when the pressure is increased. Meanwhile, the overall reaction rate was observed to decrease when the pressure was increased. This observation suggest that mass transfer limitations were not occurring. Therefore, the observed decrease in the multibranched yield at higher pressures may not be assigned to transfer limitations.

\subsubsection{Distribution of cracking products}

Figure 4 depicts the distribution of cracking products in terms of carbon number at $10 \%$ yield of cracked products at 1.1 and $4.1 \mathrm{MPa}$ total pressure. In both cases, the quasi absence of methane and ethane confirms that hydrogenolysis over the metallic sites is negligible. A roughly symmetrical and bell-shaped-like product distribution can be observed for the low-pressure condition. This is a feature of pure primary cracking. ${ }^{2}$ Contrarily, at $4.1 \mathrm{MPa}, \mathrm{C}_{3}$ to $\mathrm{C}_{7}$ products were present in higher amounts than the corresponding heavier counterparts revealing the occurrence of secondary cracking. In addition, the overcracking index, defined as the number of cracked molecules formed 
1 per $\mathrm{C}_{16}$ molecule cracked was also examined. If only pure primary cracking exists, the

2 overcracking index is equal to 2. Contrarily, if half of the cracked products undergo a

3 second cracking step, the overcracking index equals 3. At $4.1 \mathrm{MPa}$, the average

4 overcracking index was 2.14 against 2.07 at $1.1 \mathrm{MPa}$ (Fig. S3). Secondary cracking was

5 thus indeed promoted at high-pressure conditions.

6 From a mechanistic point of view, the enhanced secondary cracking can only be

7 a consequence of more consecutive acid-catalyzed steps for the cracking products. As

8 abovementioned, whenever a bifunctional catalyst is poorly-balanced, increased

9 pressure will lead to faster hydrogenation reducing then the number of consecutive steps

10 over acid sites. ${ }^{9,54}$ Hence, the results herein observed could not be explained by the

11 reaction intrinsic kinetics, as for the decrease in the maximal isomer yield.

12
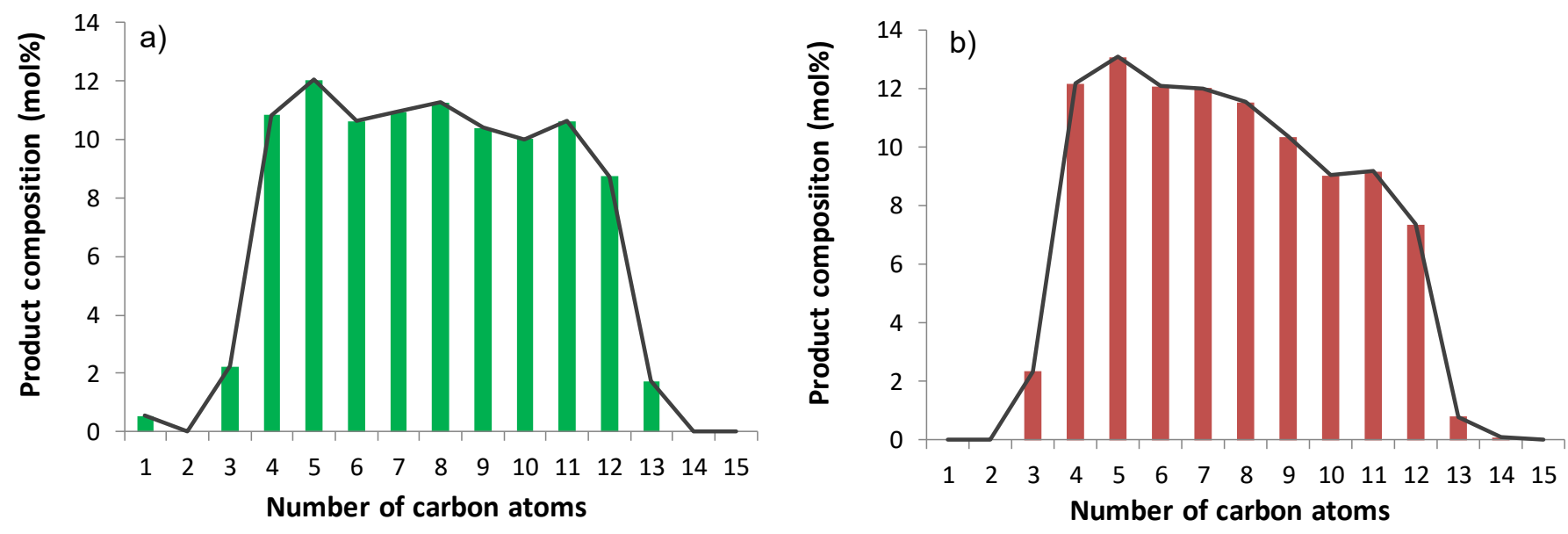

Figure 4: Molar distribution of cracked products for 10\% yield in cracking products: a) $1.1 \mathrm{MPa}$ and b)

4.1 MPa. 
$1 \quad 3.2$ Simulation of the adsorption of hydrocarbons on Beta zeolite (polymorph A)

The evolution of catalytic behavior with pressure presented herein cannot be explained through the reaction kinetics, as established by the bifunctional mechanism. However, the catalytic behavior is not controlled solely by the reaction kinetics, but also by the adsorption/desorption of reactants and products. In order to shed light on the impact of the latter, GCMC simulations were performed. The main goals of such simulations are i) to understand the confinement effect on the adsorption of the various kinds of hydrocarbons involved along the reaction, ii) to study the impact of adsorption on the evolution of the selectivities as a function of the pressure. Previous to considering the co-adsorption of mixtures, in a first step the independent behavior (adsorption isotherms) of representative pure compounds is investigated.

\subsubsection{Simulation of the adsorption of pure hydrocarbons}

The independent adsorption isotherms of n-hexadecane ( $n-C_{16}$, the reactant), 6methyl-heptadecane $\left(6 \mathrm{M}-\mathrm{C}_{15}\right.$, representative of the monobranched - MB - family), 4,4,6-trimethyl-tridecane (446M- $\mathrm{C}_{13}$, representative of the multibranched - MTB family), n-octane, and 4-methyl-heptane ( $n-C_{8}$ and $4 M-C_{7}$, representative of the cracking products - $\mathrm{CP}$ - family) were calculated by the GCMC approach (Figure 5). For the isoalkanes, central branching positions were selected as this is expected to result in greater variety in terms of adsorption properties. For a given number of carbon atoms (16 or 8), the adsorption threshold appeared to be strongly sensitive to the branching degree, with higher loading at lower pressures in the case of the linear molecules. This can likely be related to the straight nature of pores in zeolite Beta, in two directions of space. In particular, the filling of the pore with the multi-branched $\mathrm{C}_{16}$ species $\left(446 \mathrm{M}-\mathrm{C}_{13}\right)$ is strongly shifted at high pressure with respect to the two other $\mathrm{C}_{16}$ species. The maximal 
1 loading at high pressure is however about the same for all $\mathrm{C}_{16}$ molecules. As

2 expected, ${ }^{86,87} \mathrm{C}_{8}$ molecules are quantitatively adsorbed at relatively much higher

3 pressure as compared to $\mathrm{C}_{16}$ molecules, but the amount adsorbed at saturation is much

4 higher. The respective behaviors of $\mathrm{C}_{8}$ and $\mathrm{C}_{16}$ molecules are the consequences of the

5 evolution of the adsorption enthalpy and entropy with respect to the size of the

6 molecule, themselves strongly influence by the pore topology. ${ }^{80}$ Expectedly, the

7 adsorption enthalpy increases in absolute value (stronger interaction) as the number of

8 carbon atoms in the molecule increases. For large pore zeolites such as Beta, the

9 corresponding entropy loss remains moderately dependent on the chain length ${ }^{80}$, so that

10 in the end, the longer the molecule, the stronger the adsorption, and the lower the

11 saturation pressure.

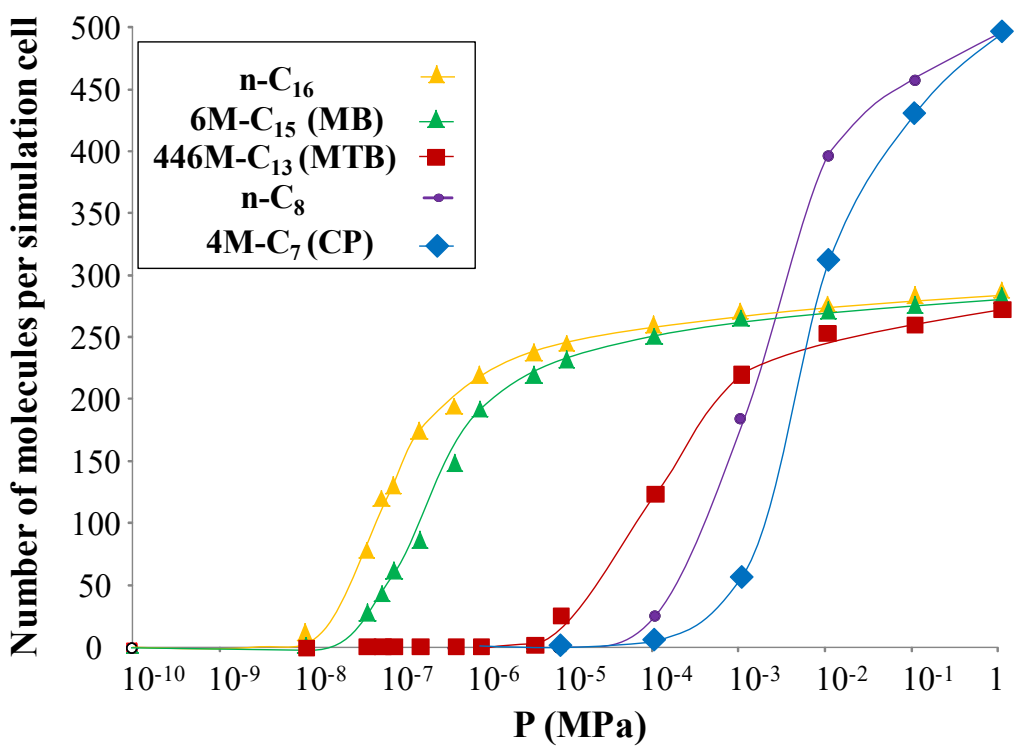

Figure 5: Adsorption isotherms obtained from GCMC calculations, for pure representative compounds at $538 \mathrm{~K}$. Lines are only guides for the eye.

The range of threshold pressures appears to be rather low if compared with the experimental pressures conditions used. In these conditions, depending however on the conversion levels, the zeolite should be close to saturation for all $\mathrm{C}_{16}$ compounds, if not 
$1 \quad \mathrm{C}_{8}$ compounds. Thus, analyzing the adsorption competition between these compounds

2 requires the explicit simulation of the adsorbed mixture properties.

\subsubsection{Simulation of the adsorption of mixtures of hydrocarbons representative of the} reaction medium

A representative mixture was chosen to mimic the reaction medium at intermediate cracking level (n-C $16: \mathrm{MB}: \mathrm{MTB}: \mathrm{CP}=1: 1: 2: 2) . \mathrm{MB}, \mathrm{MTB}$ and $\mathrm{CP}$ are represented by $6 \mathrm{M}-\mathrm{C}_{15}, 446 \mathrm{M}-\mathrm{C}_{13}$ and $4 \mathrm{M}-\mathrm{C}_{7}$ respectively. First, for comparison purposes, the equilibrium adsorption isotherms are shown in absence of $\mathrm{CP}$, over a large range of total hydrocarbon pressures (Figure 6a). Note that the total pressure (including hydrogen, not taken into account in the GCMC simulation) is much higher than the hydrocarbon partial pressure. The domains explored experimentally are indicated in the legend of each figure hereafter. Such domains were determined by considering the experimental initial $\mathrm{H}_{2} / \mathrm{Hydrocarbon}$ molar ratios of 10 and 12 at 1.1 and $4.1 \mathrm{MPa}$ total pressures respectively.

Despite the high partial pressure (corresponding to a high conversion level) of MTB species considered, this species would be not significantly adsorbed in the zeolite. On the other hand, $\mathrm{n}-\mathrm{C}_{16}$ dominates over a large pressure condition range. The results of GCMC show, hence, the following adsorption selectivity order: $n-\mathrm{C}_{16}>\mathrm{MB}>>\mathrm{MTB}$. It is worth mentioning that over the whole range of pressures considered, the pores remain saturated in hydrocarbons. In line with the present results, previous Monte Carlo investigations for $\mathrm{C}_{4}-\mathrm{C}_{9}$ alkanes in silicalite showed that, in vapor-phase, linear alkanes exhibit a higher packing efficiency. ${ }^{88,89}$ As a consequence, at a given pressure, higher loadings are achieved when replacing branched alkanes with linear ones. In short, as the loading increases, for a given carbon number, linear alkanes are expected to replace 
1 branched alkanes due to configurational entropic effects. Conversely, when pore

2 saturation becomes to be approached, adsorption of alkanes in zeolites is known to

3 become less selective. ${ }^{53,58}$ In other words, at pore saturation, all molecules would be

4 expected to have closer affinities for the zeolite, ${ }^{90}$ which is clearly not the case here.

5

6

7

8
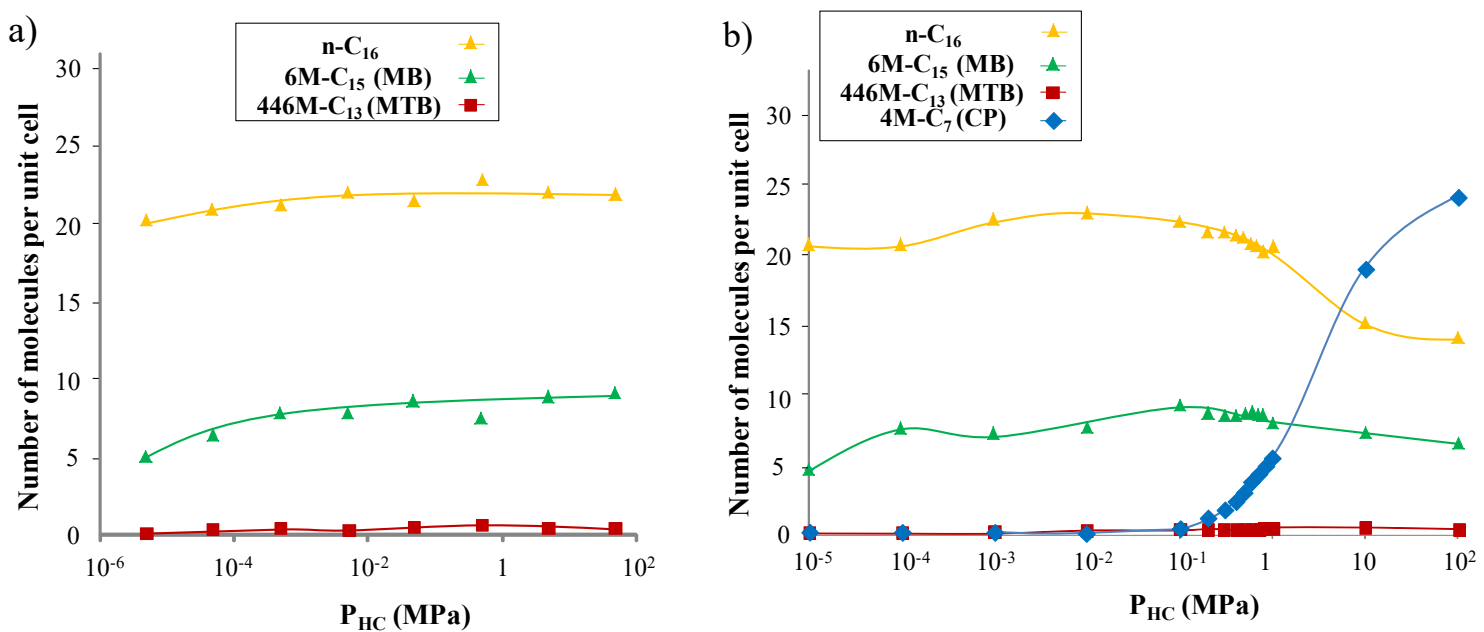

9 Figure 6: Calculated adsorption isotherms at $538 \mathrm{~K}$ (by GCMC) for a n- $\mathrm{C}_{16}$ :MB:MTB mixture

a) in absence and b) in presence of $\mathrm{CP}$. A gas phase $1: 1: 2(: 2)$ ratio for the mixture $n-\mathrm{C}_{16}: 6 \mathrm{M}$ $\mathrm{C}_{15}: 446 \mathrm{M}-\mathrm{C}_{13}\left(: 4 \mathrm{M}-\mathrm{C}_{7}\right)$, representative of the $\mathrm{n}-\mathrm{C}_{16}: \mathrm{MB}: \mathrm{MTB}(: \mathrm{CP})$ one. The "low" and "high" pressures conditions corresponds to about $10^{-1}$ and $4.10^{-1} \mathrm{MPa}$, respectively. 
1 (Figure 6b). In this way, $4 \mathrm{M}-\mathrm{C}_{7}$ is almost absent at low pressures and progressively

2 replaces the longer hydrocarbon compounds. This effect was more pronounced at high

3 gas phase CP concentration. Despite the higher partial pressures considered for CP in

4 both models, such a behavior is consistent with the shift in threshold pressure with

5 respect to $\mathrm{C}_{16}$ species already observed for pure compounds. Starting from a

6 hydrocarbon pressure of $\sim 10^{-1} \mathrm{MPa}$ (corresponding to a total pressure close to $1 \mathrm{MPa}$ ),

7 their concentration in the zeolite started to increase. CP even virtually dominated in the

8 solid between 1 and $10 \mathrm{MPa}$ of hydrocarbon partial pressure. This is mainly associated

9 to a decrease in $\mathrm{n}^{-\mathrm{C}_{16}}$ and $\mathrm{MB}$ concentrations (to a much lower extent in the case of the

10 latter) within the pores.

Due to the non-monotonous variation of concentrations with pressure, the behavior of the adsorbed phase can be considered far away from ideality. In order to understand the effect of pressure in the intrinsic adsorption selectivity (i.e. decoupled from composition), the results are presented in the form of separation factors as function of the hydrocarbon partial pressure in Figure 7. The corresponding separation factors between $\mathrm{CP}$ or $n-\mathrm{C}_{16}$, and the ensemble $\mathrm{MB}+\mathrm{MTB}$ are calculated according to

17 equation $2, \mathrm{y}_{\mathrm{i}}$ depicting the gas phase molar fraction, $\mathrm{C}_{\mathrm{i}}^{\text {ads }}$ the adsorbed concentration, for $\mathrm{i}=\mathrm{CP}$ or $\mathrm{n}-\mathrm{C}_{16}$.

$$
S F_{i}=\frac{C_{i}^{a d s} \cdot\left(y_{M B}+y_{M T B}\right)}{\left(C_{M B}^{a d s}+C_{M T B}^{a d s}\right) \cdot y_{i}}
$$

Despite the possible deviation associated to the molecular model parameterization

21 (additional details can be found in SI1), the obtained results in the considered range of experimental conditions unravel an important impact of the hydrocarbon partial pressure on the adsorption selectivity. 
2 expense of $n-C_{16}$. Meanwhile, the adsorption of MB is much less affected. Focusing 3 solely in entropy, linear alkanes have a higher packing efficiency than the

4 corresponding structural isomers. ${ }^{88,89}$ Therefore, CP would be expected to preferentially

5 replace branched alkanes (in this case $\mathrm{MB}$ ) rather than linear ones with the same carbon

6 number. ${ }^{91}$ However, when confinement increases (i.e. pore size and kinetic diameter of

7 molecules become commensurable), cases exist in which branched isomers (namely

8 with the methyl group in the central position) adsorb preferentially. ${ }^{91,92}$ Finally,

9 although a model with different mixture composition yielded qualitatively similar

10 results (see Fig. S2 in SI), significant changes in the mixture composition might also

11 have an effect in the intrinsic adsorption selectivity. ${ }^{93}$

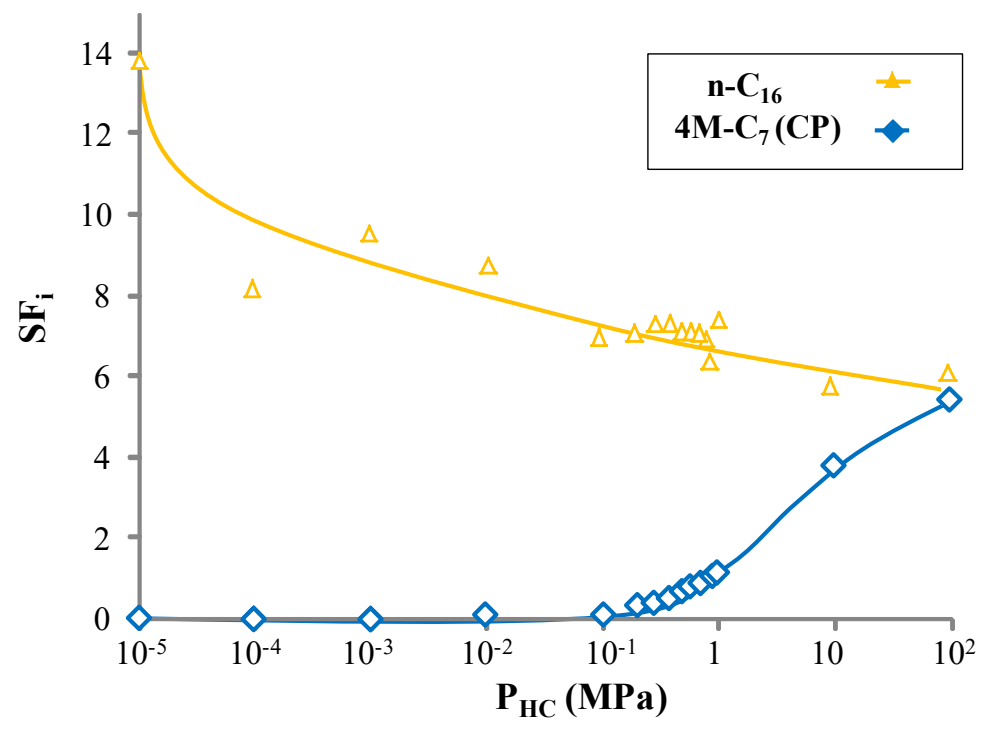

$14 \quad$ Figure 7: Evolution of the separation factor (defined by equation 2) as a function of the

15 hydrocarbon pressure at $538 \mathrm{~K}$, as simulated by GCMC. Gas phase concentration ratio in n-

$16 \mathrm{C}_{16}: 6 \mathrm{M}-\mathrm{C}_{15}: 446 \mathrm{M}-\mathrm{C}_{13}: 4 \mathrm{M}-\mathrm{C}_{7}$ mixtures: 1:1:2:2 on *BEA zeolite. Lines are guide for the eyes. 


\section{Discussion} $5 \quad \mathrm{C}_{16}$ at high pressure, which was attributed to a higher apparent reactivity of such

The experimental catalytic results revealed in Section 3.1 clearly show a decrease in $\mathrm{C}_{16}$ isomer yield when increasing the total pressure for a well-balanced $\mathrm{Pt} / \mathrm{H}-\mathrm{Beta}$ catalyst. This decrease is mainly due to a decrease in the formation of monobranched compounds towards consecutive reactions. The latter was well rendered by the use of a very simple kinetic model. Meanwhile, the study of the adsorption behavior by GCMC simulations disclosed a change in the adsorption affinity of hydrocarbons in the zeolite as a function of pressure. In order to unequivocally relate the adsorption behavior to the catalytic results, it is convenient to make use of the bifunctional mechanism and the corresponding rate equations, now using a much more refined model as compared to the previous one.

For a well-balanced catalyst, the dehydrogenation of paraffins into olefins is in quasi-equilibrium and the rate-determining steps (RDS) are isomerization and cracking taking place on the acid sites. ${ }^{9-11}$ As detailed in Table 2, a paraffin (with a degree of isomerization $\mathrm{j}$ ) is considered to be firstly physisorbed in the zeolite pores and then dehydrogenated on the metal sites (only the global reaction is written, as equilibrium is assumed). The corresponding olefin chemisorbs over a Brønsted site of the zeolite generating a carbenium ion. The latter subsequently undergoes skeletal rearrangements or carbon-carbon bond rupture. ${ }^{2}$ The formed olefins follow the inverse reaction pathway being first deprotonated, then hydrogenated into a paraffin. Finally the paraffin is desorbed. However, acknowledging both the rate-determining character and irreversibility of isomerization and cracking, the steps after these reactions do not take part in the rate law (and thus were not explicitly written in Table 2). The concentration 
1 of vacant acid sites, labelled [a], depends on the fraction of vacant sites and the amount

2 of acid sites per catalyst mass, $\mathrm{n}_{\mathrm{Al}}$. The concentration of adsorbed paraffins, $\left[\mathrm{P}_{\mathrm{j}}^{\text {ads }}\right]$ is a

3 function of total pressure, $\mathrm{P}_{\mathrm{T}}$, and composition in hydrocarbons in the zeolite,

4 particularly cracking products, $\mathrm{y}_{\mathrm{CP}}$ ' as shown by GCMC calculations.

5 Table 2: Reaction mechanism of a paraffin over a well-balanced bifunctional catalyst. The

6 deprotonation then hydrogenation then desorption steps of isomerized and cracked products are assumed to be at equilibrium.

Adsorption

$$
P_{j} \rightleftarrows P_{j}^{a d s}
$$

$C_{P_{j}}^{a d s} \cong f\left(P_{T}, y_{P_{j}}\right)$

Equation 2

Dehydrogenation/

$P_{j}^{a d s} \rightleftarrows O_{j}+H_{2}$

Hydrogenation

$K_{j}^{D H}=\frac{C_{O_{j}}^{a d s} P_{H_{2}}}{C_{P_{j}}^{a d s}}$

Equation 3

Protonation

$O_{j}^{a d s}+a \rightleftarrows O_{j}^{+}+a^{-}$

$K_{j}^{\text {prot }}=\frac{C_{O_{j}}^{+}}{C_{O_{j}}^{a d s}[a]}$

Equation 4

Isomerization

$$
O_{j}^{+} \rightarrow O_{j+1}^{+}
$$

RDS

Cracking

$$
O_{j}^{+} \rightarrow O_{m}^{+}+O_{n}
$$

RDS

If the steps of transformation of carbenium ions are assumed rate-limiting compared to the adsorption/desorption of olefins, the reaction rate over acid sites is given by Eq. 5, where $\mathrm{k}_{\mathrm{a}}$ is either kinetic constant for isomerization or cracking reaction. It is worth mentioning that the Langmuir-Hinshelwood formalism cannot be (fully) applied in this case, due to the non-ideal physisorption behavior for paraffin mixtures.

3 To obviate any assumptions on physisorption, the concentration of adsorbed paraffins 4 was explicitly accounted in the reaction rate.

$$
r_{a}=k_{a} K_{j}^{D H} K_{j}^{p r o t}[a] \frac{C_{P_{j}}^{a d s}}{P_{H_{2}}}
$$


1 The coverage of acid sites was demonstrated to be very low in the hydroconversion of 2 paraffins ${ }^{94}$, in accordance with the low concentration of olefins. Therefore, the

3 concentration of vacant acid sites can be approximated by the total concentration of acid

4 sites, $\mathrm{n}_{\mathrm{Al}}$ and the rate of an acid-catalyzed step for any paraffin in the reaction medium

5 is given by Eq. 6 .

$$
r_{a}=k_{a} K_{j}^{D H} K_{j}^{p r o t} n_{A l} \frac{C_{P_{j}}^{a d s}}{P_{H_{2}}}
$$

6 Considering the same product lumps as before (Scheme 1), the continuity equations for $7 \quad n-\mathrm{C}_{16}$ and its isomers over the catalyst mass (w) can be written (Eq. 7)

$$
\begin{gathered}
\frac{d F_{n-C_{16}}}{d w}=-r_{i s o m} \\
\frac{d F_{i-C_{16}}}{d w}=r_{\text {isom }}-r_{\text {crack }}
\end{gathered}
$$

8 Writing the rate laws for isomerization of $n$-hexadecane and cracking of its isomers

9 based on Eq. 6, Eqs. 9 and 10 can be obtained. Whereas the (intrinsic) kinetic constants 10 for surface reactions are not expected to be influenced by pressure changes, and can be 11 then grouped into lumped kinetic constants (k'), the molecular simulation results 12 revealed that physisorbed concentrations might be. Substituting the rate equations (Eqs. 139 and 10) into the continuity equations and dividing Eq. 8 by Eq. 7, the variation of the 14 yield of $\mathrm{C}_{16}$ isomers upon an incremental variation in conversion as a function of kinetic parameters and species concentrations becomes explicit (Eq. 11).

$$
\begin{aligned}
& r_{i s o m}=k_{i s o m} K_{n-C_{16}}^{D H} K_{n-C_{16}}^{\text {prot }} n_{A l} \frac{C_{n-C_{16}}^{a d s}}{P_{H_{2}}}=k_{i s o m}^{\prime} \frac{C_{n-C_{16}}^{a d s}}{P_{H_{2}}} \\
& r_{\text {crack }}=k_{\text {crack }} K_{i-C_{16}}^{D H} K_{i-C_{16}}^{\text {prot }} n_{A l} \frac{C_{i-C_{16}}^{a d s}}{P_{H_{2}}}=k_{\text {crack }}^{\prime} \frac{C_{i-C_{16}}^{a d s}}{P_{H_{2}}}
\end{aligned}
$$




$$
\frac{d Y_{i-C_{16}}}{d X}=\frac{d F_{i-C_{16}}}{d F_{n-C_{16}}}=1-\frac{k_{\text {crack }}^{\prime} C_{i-C_{16}}^{a d s}}{k_{i s o m}^{\prime} C_{n-C_{16}}^{a d s}}
$$

The GCMC molecular simulations have shown that hydrocarbons mixtures

2 behave differently from pure hydrocarbons and, more importantly, that the affinity of

3 each compound to the zeolite can evolve as a function of the pressure depending on the

4 branching degree and carbon number. In Figure 8a, this evolution is taken into account

5 to simulate the evolution of the derivative of $\mathrm{Y}_{\mathrm{i}-\mathrm{C} 16}$ with respect to that of conversion

6 based on the kinetic model (Eq. 11), for a given conversion (83\%), corresponding to the

7 hydrocarbon mixture chosen for GCMC simulations. First of all, as expected, the higher

8 ratio between isomerization and cracking lumped kinetic constants, the lower the slope

9 of the $\mathrm{Y}_{\mathrm{i}-\mathrm{C} 16}$ versus conversion curve. Regardless of this ratio (which was unknown), the

10 overall trend pointed to less steep increase yield of $\mathrm{C}_{16}$ with conversion for higher total

11 pressures. Therefore, the $\mathrm{dY}_{\mathrm{i}-\mathrm{C} 16} / \mathrm{dX}$ would become zero at a lower conversion and so

12 the maximum of $\mathrm{C}_{16}$ isomers yield would be reached at lower conversion. Taking into

13 account the known shape of the evolution of $\mathrm{C}_{16}$ isomers yield with conversion ${ }^{11,54,95}$,

14 the maximum of $\mathrm{C}_{16}$ isomers yield would hence be lower as total pressure increases, as

15 observed experimentally (Figure 2).
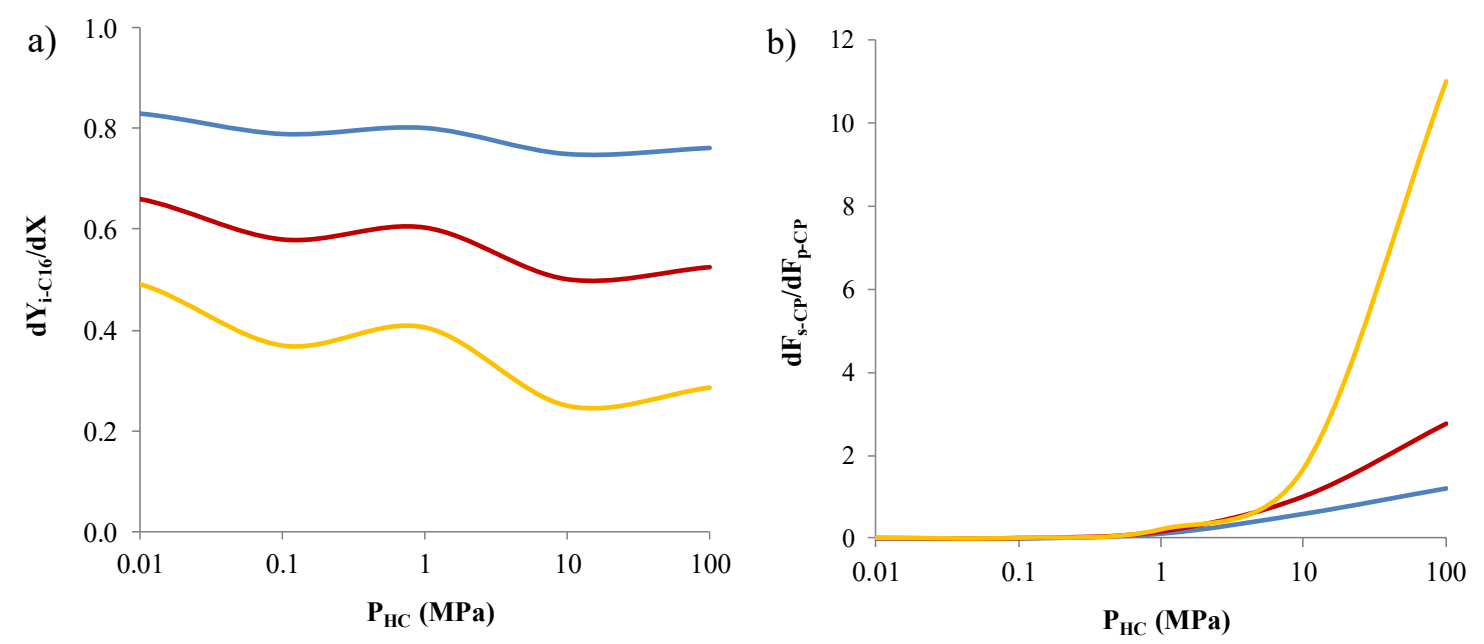
Figure 8: a) Evolution of the derivative of the yield with respect to the conversion at $83 \%$ conversion as function of the total pressure, for various $\boldsymbol{k}_{\text {crack }}^{\text {app }} / \boldsymbol{k}_{\text {isom }}^{\text {app }}: 0.5(-), 1.0(-), 1.5$ (-). b) Evolution of the derivative of the yield with respect to the conversion at $83 \%$ conversion as function of the total pressure, for various $\boldsymbol{k}_{\boldsymbol{s}-\text { crack }}^{\text {app }} / \boldsymbol{k}_{\boldsymbol{p - c r a c k}}^{\text {app }}: 0.15(-), 0.20($ $-), 0.25(-)$. Simulations based on a dual-function kinetic mode ${ }^{11}$ for a well-balanced catalyst (via a) Eq. 11 and b) Eq. 16) and on the GCMC results (via the evolution of partial pressures with total pressure, as depicted in Figure 6 b) Erreur ! Source du renvoi introuvable.

From a mechanistic point of view, when total pressure increases, $\mathrm{C}^{\mathrm{ads}}{ }_{\mathrm{n}-\mathrm{C} 16}$ decreases as compared to $\mathrm{C}^{\text {ads }}{ }_{M B}$ and $\mathrm{C}^{\text {ads }}{ }_{\text {MTB}}$, and therefore $\mathrm{C}^{\text {ads }}{ }_{\text {i-C16 }}$ (Figure 7). The rate of MB and MTB cracking is, hence, favored as compared to the isomerization of $n$ hexadecane (Eqs. 9-11). Such change on the relative adsorbed concentrations of $n-C_{16}$ and $i-\mathrm{C}_{16}$ at higher pressures results, hence, in a reduction of the selectivity towards $\mathrm{C}_{16}$ isomers at higher pressures. In the same way, the significant increase in cracked products observed when increasing pressure can be directly related to the drop in the $\mathrm{SF}_{\mathrm{n}-\mathrm{C} 16}$ with pressure. It is worth underlining that this is counter intuitive when reasoning according to the bulkiness of the molecules and the adsorption isotherms of the pure compounds. In fact, it can only be explained by the interplay of lighter hydrocarbons (cracking products) in the adsorption of heavier hydrocarbons $\left(n-\mathrm{C}_{16}, \mathrm{MB}\right.$ and MTB).

As mentioned in the Introduction, there is no consensus in literature regarding the isomerization selectivity of H-Beta zeolite. Some studies suggested high selectivity towards feed isomers ${ }^{20,42,43,50,51}$ while others disclosed high cracking yields even for intermediate levels of conversion ${ }^{38,53}$. Unfortunately, as most of those studies do not mention if the bifunctional catalyst studied is properly balanced or not, their data cannot 
1 be directly compared. Therefore, the focus was put on two studies (carried out by some

2 of us) for which well-balanced $\mathrm{Pt} / \mathrm{H}$-Beta catalysts were tested in the

3 hydroisomerization of $n$-hexadecane. It should be nonetheless mentioned that Batalha et

4 al. obtained the referred result over a composite of $\mathrm{H}$-Beta with $\alpha-\mathrm{Al}_{2} \mathrm{O}_{3} .{ }^{15}$ The 5 maximum feed isomers yield is plotted against $n$-hexadecane partial pressure in Figure 69 and compared to the current results.

8 Figure 9: Maximum yield of $\mathrm{C}_{16}$ isomers as a function of $n$-hexadecane inlet partial pressure for

$9 \mathrm{Pt} / \mathrm{H}-$ Beta catalysts. Batalha et al. (४), ${ }^{15}$ Mota $(\diamond),{ }^{96}$ and this study: at $1.1(0)$ and $4.1 \mathrm{MPa}($ 10

The previous results are in line with the high selectivity at high conversion of $\mathrm{Pt} / \mathrm{H}-\mathrm{Beta}$ at low pressures observed in this study. In other words, whenever the partial pressure of $n$-hexadecane is below $100 \mathrm{kPa}$ and the bifunctional catalyst is wellbalanced, $\mathrm{H}$-Beta zeolite can achieve great $\mathrm{C}_{16}$ isomers yield. Conversely, this study demonstrates that high partial pressures can be detrimental to feed isomers yield over $\mathrm{Pt} / \mathrm{H}$-Beta catalysts, due to the stronger stabilization of branched $\mathrm{C}_{16}$ isomers inside the pores compared to the linear isomer. Interestingly enough, the data by Mota et al., ${ }^{96}$ included in Figure 9, was obtained using $n$-heptane as diluent. This might explain, at the

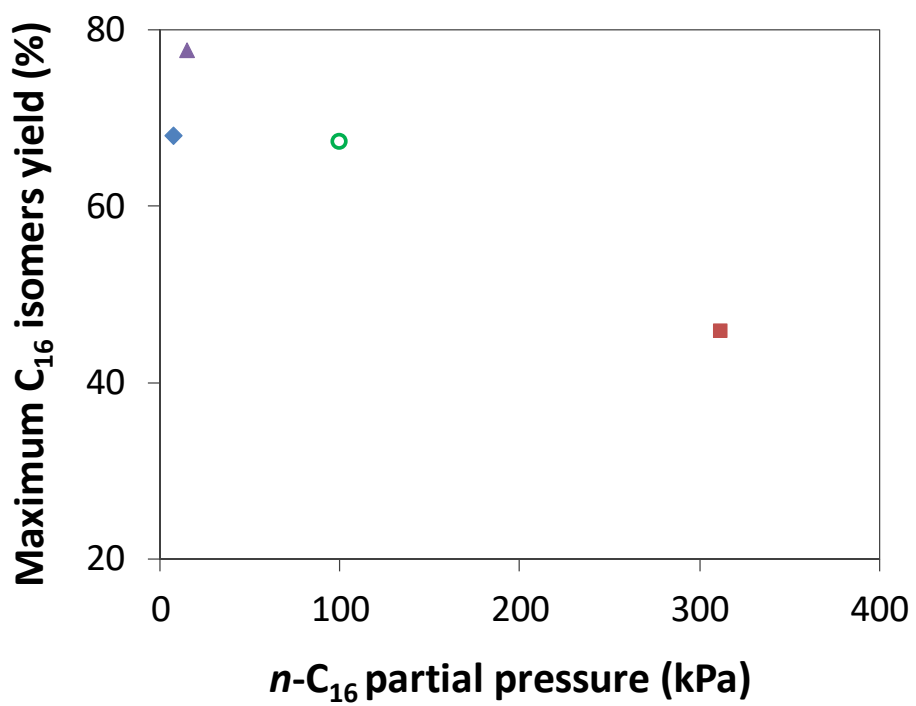


1 light of our results, the lower $\mathrm{C}_{16}$ isomer yield as compared to the one obtained by

2 Batalha et al. ${ }^{15}$ Taking a broader perspective, the pressure-dependence of H-Beta-based

3 catalysts selectivity might explain the contradictory results reported in literature on the

4 hydroisomerization behavior of $\mathrm{H}$-Beta zeolite and the minor industrial application of

$5 \mathrm{Pt} / \mathrm{H}$-Beta catalysts. Furthermore, most of the more dated studies reporting promising

6 results for $\mathrm{Pt} / \mathrm{H}$-Beta catalysts were performed over shorter alkanes, for which

7 confinement effects are expected to be less predominant.

8

The enhanced secondary cracking at high-pressure conditions, can be mechanistically grasped by decoupling $\mathrm{CP}$ lump into primary cracking products, $\mathrm{p}-\mathrm{CP}$, and secondary cracking products, s-CP (see Scheme 2). The respective continuity equations (Eqs. 12 and 13) depend, obviously, on the both primary and secondary cracking reaction rates. Those can be explicitly written via Eq. 6 (Eqs. 14 and 15), yielding an expression relating the formation of both product lumps (Eqs. 16). As represented in Figure 8b, the derivative of the flowrate of secondary CP with respect to the one of primary $\mathrm{CP}$ increases with higher ratios between the lumped secondary cracking constant and the primary one. More importantly, according to the kinetic simulations, for a fixed conversion level $(83 \%)$, increasing the total pressure would lead to a significant augmentation of the net rate of formation of secondary $\mathrm{CP}$, as compared to primary ones. This is in line with the clear presence of secondary cracking at 4.1 $\mathrm{MPa}$ contrarily to $1.1 \mathrm{MPa}$ (Figure 4 and Figure S4).

$$
\begin{array}{cr}
\mathrm{n}-\mathrm{C}_{16} \stackrel{\mathbf{r}_{\text {isom }}}{\longrightarrow} \mathrm{i}-\mathrm{C}_{16} \stackrel{\mathbf{r}_{\mathrm{p} \text {-crack }}}{\longrightarrow} \mathrm{p}-\mathrm{CP} \stackrel{\mathbf{r}_{\mathrm{s}-\text { crack }}}{\longrightarrow} \mathrm{s}-\mathrm{CP} & \text { Scheme 2 } \\
\frac{d F_{p-C P}}{d w}=r_{p-\text { crack }}-r_{s-\text { crack }} & \text { Equation 12 }
\end{array}
$$




$$
\begin{array}{cc}
\frac{d F_{s-C P}}{d w}=r_{s-\text { crack }} & \text { Equation } 13 \\
r_{p-\text { crack }}=k_{p-\text { crack }} K_{i-C_{16}}^{D H} K_{i-C_{16}}^{p r o t} n_{A l} \frac{C_{i-C_{16}}^{a d s}}{P_{H_{2}}}=k_{p-\text { crack }}^{\prime} \frac{C_{i-C_{16}}^{a d s}}{P_{H_{2}}} & \text { Equation } 14 \\
r_{s-\text { crack }}=k_{s-\text { crack }} K_{p-C P}^{D H} K_{p-C P}^{p r o t} n_{A l} \frac{C_{p-C P}^{a d s}}{P_{H_{2}}}=k_{s-\text { crack }}^{\prime} \frac{C_{p-C P}^{a d s}}{P_{H_{2}}} & \text { Equation 15 } \\
\frac{d F_{s-C P}}{d F_{p-C P}}=\left(\frac{k_{p-c r a c k}^{\prime} C_{i-C_{16}}^{a d s}}{k_{s-\text { crack }}^{\prime} C_{p-C P}^{a d s}}-1\right)^{-1} & \text { Equation 16 }
\end{array}
$$

1 According to GCMC calculations, $\mathrm{C}_{\mathrm{CP}}^{\mathrm{ads}}$ is also observed to increase with pressure 2 relatively to $\mathrm{C}_{\text {MB }}^{\text {ads }}$ and $\mathrm{C}_{\text {MTB }}^{\text {ads }}$. Taking this into account, increasing pressure will lead 3 to faster cracking of primary cracked products (Eq. 15) as compared to the cracking of $4 \mathrm{C}_{16}$ isomers (Eq. 14). Therefore, secondary cracking, at comparable yields of $\mathrm{C}_{16}$ 5 isomers, will be enhanced when increasing pressure. As a matter of fact, the 6 predominance of primary cracking is typically explained by the enhanced adsorption of 7 alkanes with increased chain length, which favors the conversion of the heaviest 8 molecules. ${ }^{86}$ Nonetheless, the presence of secondary cracking has been often attributed 9 to the vanishing of such selective adsorption of the heavier molecules when the pores of 10 the zeolite are saturated, ${ }^{90,58}$ particularly over Beta zeolite. ${ }^{53}$ In such way, at pore saturation, the reactivity of alkanes with the same degree of branching becomes similar. That is not, though, what the GCMC calculations put forward. Zeolite pores are saturated during the whole range of studied pressures and yet the adsorption selectivity is kept. Solely for partial pressures of hydrocarbons above $0.1 \mathrm{kPa}$, the adsorption of cracked products turns out to be relevant and it only matches that of $n$-hexadecane and its isomers in the $1-10 \mathrm{kPa}$ range.

In summary, adsorption of alkanes in the zeolite Beta seems to be highly dependent on both pressure and mixture effects. In particular, the presence of light (cracked) 
1 products was observed to decrease the adsorption of linear reactant molecules rather

2 than the corresponding branched isomers, for sufficiently high pressures. The lower

3 selectivity towards feed isomers and primary cracking at higher pressures observed for a

4 well-balanced $\mathrm{Pt} / \mathrm{H}$-Beta catalyst was in line with the disfavored adsorption of the linear

5 reactant and the favored adsorption of cracked products. The mixture effects between

6 hydrocarbons and the impact of pressure on those are, hence, of utmost importance on

7 catalyst selectivity in hydroconversion processes. The approach developed here opens

8 the door to selectivity predictions for a large range of catalytic materials, ${ }^{62,63}$ provided

9 operating conditions, in particular reactant and products partial pressures, are also

10 included in the material screening. Whereas as of today more detailed simulations

11 would be unfeasible for screening purposes, additional studies featuring all possible

12 existing isomers might lead to more quantitative results, particularly if these isomers

13 adsorb more favorably in the Beta micropores reducing even more the adsorption of the

14 reactant, and identification of critical properties (e.g. kinetic diameter) for the herein

15 disclosed competitive adsorption.

\section{Conclusion}

The focus of this study was hold on the effect of pressure over the performances for $\mathrm{n}-\mathrm{C}_{16}$ hydroconversion obtained for a well-balanced $\mathrm{Pt} / \mathrm{H}$-Beta catalyst. In order to obtain clear insights into a possible effect of the adsorption properties on the catalytic behavior, GCMC molecular simulation technique was combined with catalytic tests and kinetic analysis.

The catalytic evaluation revealed a detrimental impact of total pressure on the yield of $\mathrm{C}_{16}$ isomers yield for a well-balanced $\mathrm{Pt} / \mathrm{H}$-Beta catalyst. Consecutive cracking was also favored when the total pressure increased. In hydroconversion, high pressures are 
1 known to favor the balance of the acid function by the metal one. For poor-balanced

2 catalysts, this is expected to result in improved feed isomers yields. The pressure effect

3 observed herein occurred in the opposite direction.

When considering a mixture representative of the reaction medium, the GCMC

5 simulations showed an evolution of the adsorption selectivity with pressure. In

6 particular, when pressure was increased, the light (cracked) products became

7 increasingly adsorbed at the expense of $n-C_{16}$ molecules. $\mathrm{C}_{16}$ branched isomers were

8 only marginally impacted. The lower selectivity towards feed isomers at higher

9 pressures observed was, hence, explained by a greater relative reactivity of $\mathrm{C}_{16}$ isomers

10 as compared to $n$-hexadecane. Likewise, the enhanced adsorption of cracked products

11 relative to $\mathrm{C}_{16}$ isomers is believed to be at the origin of the amplified secondary cracking at higher pressures. It is worth noting that these effects were only observed when cracked products were introduced into the mixture of $\mathrm{C}_{16}$. Therefore, the interplay between the (light) cracked products and the (heavy) $n$-hexadecane, in the pores of beta zeolite, is proposed to be at the origin of the pressure effect in catalyst selectivity. These insights enabled, as well, to shed light on the contradiction between the outstanding hydroisomerization behavior of $\mathrm{Pt} / \mathrm{H}$-Beta catalysts reported in most studies and the minor use of H-Beta in industrial practice. The considerably lower partial pressures employed in the former potentially explain this paradox.

More generally, the catalytic behavior of Pt/zeolite catalysts in the hydroconversion of high carbon number alkanes might depend strongly on the complex interplay between hydrocarbons subjected to confinement in the zeolite pore. Further studies on the physisorption of alkanes mixtures representative of the hydroconversion 
1 reaction medium in order to understand the competition between hydrocarbons is of

2 particular interest.

\section{Corresponding Authors}

$4 \quad$ Emails: pedro.f.mendes@tecnico.ulisboa.pt; christophe.bouchy@,ifpen.fr

5

$6 \quad$ Author Information

7 Pedro S. F. Mendes's present address: Laboratory for Chemical Technology, Ghent

8 University, B-9052 Ghent, Belgium.

\section{$9 \quad$ Notes}

10 The authors declare no competing financial interest.

\section{Acknowledgements}

12 The authors thank A. Gregório and M. Moscovici-Mirande for the work on $n-\mathrm{C}_{16}$

13 hydroisomerization. Fundação para a Ciência e Tecnologia granted financial support 14 through CQE (Project UID/QUI/00100/2013) and P.S.F. Mendes' PhD fellowship 15 (SFRH/BD/87927/2012). The GCMC calculations were performed on the ENER110 16 supercomputer of IFP Energies nouvelles. 


\section{References}

1 F. Bertoncini, A. Bonduelle-Skrzypczak, J. Francis and E. Guillon, Hydrocracking, in Catalysis by Transition Metal Sulphides, ed. H. Toulhoat and P. Raybaud, Ed. Technip, Paris, 2013, pp 609-677.

2 J. Weitkamp, Catalytic Hydrocracking-Mechanisms and Versatility of the Process, ChemCatChem, 2012, 4, 292-306.

3 E. T. C. Vogt, G. T. Whiting, A. Dutta Chowdhury and B. M. Weckhuysen, Zeolites and Zeotypes for Oil and Gas Conversion, in Advances in Catalysis, ed. F. C. Jentoft, Academic Press, 2015, pp 143-314.

4 C. Bouchy, G. Hastoy, E. Guillon and J. A. Martens, Fischer-Tropsch Waxes Upgrading via Hydrocracking and Selective Hydroisomerization, Oil Gas Sci. Technol. 2009, 64, 91-112.

5 A. M. Robinson, J. E. Hensley, and J. W. Medlin, Bifunctional Catalysts for Upgrading of Biomass-Derived Oxygenates, ACS Catal., 2016, 6, 5026-5043.

6 J. A. Martens, D. Verboekend, K. Thomas, G. Vanbutsele, J.-P. Gilson and J. Pérez-Ramírez, Hydroisomerization of Emerging Renewable Hydrocarbons using Hierarchical Pt/H-ZSM-22 Catalyst, ChemSusChem, 2013, 6, 421-425.

7 International Energy Outlook 2017; U.S. Energy Information Administration: Washington, 2017.

8 P. S. F. Mendes, J. M. Silva, M. F. Ribeiro, A. Daudin and C. Bouchy, From powder to extrudate zeolite-based bifunctional hydroisomerization catalysts, J. Ind. Eng. Chem., 2018, 62, 72-83.

9 F. Alvarez, F. R. Ribeiro, G. Perot, C. Thomazeau and M. Guisnet, Hydroisomerization and hydrocracking of alkanes - Influence of the balance between acid and hydrogenating functions on the transformation of n-decane on PtHY catalysts, J. Catal., 1996, 162, 179-189.

10 M. Guisnet, "Ideal” bifunctional catalysis over Pt-acid zeolites, Catal. Today 2013, 218-219, 123-134.

11 P. S. F. Mendes, J. M. Silva, M. F. Ribeiro, P. Duchêne, A. Daudin and C. Bouchy, Quantification of metal-acid balance in hydroisomerization catalysts: a step further towards catalyst design, AIChE J., 2017, 63, 2864-2875.

12 E. Gutierrez-Acebo, C. Leroux, C. Chizallet, Y. Schuurman and C. Bouchy, Metal/Acid Bifunctional Catalysis and Intimacy Criterion for Ethylcyclohexane Hydroconversion, ACS Catal., 2018, 8, 6035-6046. controlled synthesis of metal-acid bifunctional catalysts, J. Catal., 2016, 342, 203-212. 
114 P. B. Weisz, Polyfunctional Heterogeneous Catalysis, in Advances in Catalysis,

2 ed. D. D. Eley et al., Academic Press, 1962, 13, pp. 137-190.

315 N. Batalha, L. Pinard, C. Bouchy, E. Guillon and M. Guisnet, n-Hexadecane 4 hydroisomerization over Pt-HBEA catalysts. Quantification and effect of the intimacy

5 between metal and protonic sites, J. Catal., 2013, 307, 122-131.

616 J. Zecevic, G. Vanbutsele, K. P. de Jong and J. A. Martens, Nanoscale intimacy 7 in bifunctional catalysts for selective conversion of hydrocarbons, Nature, 2015, 528, $8245-248$.

917 O. Ben Moussa, L. Tinat, X. Jin, W. Baaziz, O. Durupthy, C. Sayag, J. 10 Blanchard, Heteroaggregation and Selective Deposition for the Fine Design of 11 Nanoarchitectured Bifunctional Catalysts, ACS Catal., 2018, 8, 6071-6078.

1218 P. S. F. Mendes, F. M. Mota, J. M. Silva, M. F. Ribeiro, A. Daudin and C.

13 Bouchy, A systematic study on mixtures of Pt/zeolite as hydroisomerization catalysts, 14 Catal. Sci. Technol., 2017, 7, 1095-1107.

1519 H. Deldari, Suitable catalysts for hydroisomerization of long-chain normal 16 paraffins, Appl. Catal. A, 2005, 293, 1-10.

$1720 \quad$ J. A. Martens, M. Tielen and P. A. Jacobs, Relation Between Paraffin

18 Isomerisation Capability and Pore Architecture of Large-Pore Bifunctional Zeolites, 19 Stud. Surf. Sci. Catal., 1989, 46, 49-60.

2021 J. A. Martens, R. Parton, L. Uytterhoeven, P. A. Jacobs and G. F. Froment, 21 Selective conversion of decane into branched isomers. A comparison of platinum/ZSM22 22, platinum/ZSM-5 and platinum/USY catalysts, Appl. Catal., 1991, 76, 95-116.

2322 T. L. M. Maesen, M. Schenk, T. J. H. Vlugt, J. P. de Jonge and B. Smit, The 24 Shape Selectivity of Paraffin Hydroconversion on TON-, MTT-, and AEL-Type Sieves, 25 J. Catal., 1999, 188, 403-412.

2623 V. M. Akhmedov and S. H. Al-Khowaiter, Recent advances and future aspects 27 in the selective isomerization of high n-alkanes, Catal. Rev., 2007, 49, 33-139.

2824 L. B. McCusker and C. Baerlocher, Zeolite structures, Stud. Surf. Sci. Catal., $292005,137,41-64$.

3025 T. F. Degnan, The implications of the fundamentals of shape selectivity for the 31 development of catalysts for the petroleum and petrochemical industries, J. Catal., 32 2003, 216, 32-46.

3326 J. Hagen, Industrial Catalysis. A Practical Approach, Wiley, Weinheim, 2006.

3427 C. R. Marcilly, Where and how shape selectivity of molecular sieves operates in 35 refining and petrochemistry catalytic processes, Top. Catal., 2000, 13, 357-366. 
128 S. M. Csicsery, Shape-selective catalysis in zeolites, Zeolites, 1984, 4, 202-213.

229 E. G. Derouane, Zeolites as solid solvents, J. Mol. Catal. A: Chem., 1998, 134, $329-45$.

$430 \quad$ R. Gounder and E. Iglesia, The catalytic diversity of zeolites: confinement and

5 solvation effects within voids of molecular dimensions, Chem. Commun., 2013, 49, $6 \quad 3491-3509$.

731 G. Sastre and A. Corma, The confinement effect in zeolites, J. Mol. Catal. A:

8 Chem., 2009, 305, 3-7.

932 D. M. Ruthven, Fundamentals of Adsorption Equilibrium and Kinetics in 10 Microporous Solids, in Adsorption and Diffusion, ed. H. G. Karge and J. Weitkamp, 11 Springer, Berlin, Heidelberg, 2008, pp 1-43.

1233 E. G. Derouane, The energetics of sorption by molecular sieves, Chem. Phys. 13 Lett., 1987, 142, 200-204.

1434 R. Gounder and E. Iglesia, The Roles of Entropy and Enthalpy in Stabilizing 15 Ion-Pairs at Transition States in Zeolite Acid Catalysis, Accounts Chem. Res. 2012, 45, $16 \quad 229-238$.

1735 E. G. Derouane, Surface curvature effects in physisorption and catalysis by 18 microporous solids and molecular sieves, J. Catal., 1988, 110, 58-73.

1936 A. Janda, B. Vlaisavljevich, L.-C. Lin, B. Smit and A. T. Bell, Effects of Zeolite 20 Structural Confinement on Adsorption Thermodynamics and Reaction Kinetics for 21 Monomolecular Cracking and Dehydrogenation of n-Butane, J. Am. Chem. Soc., 2016, 22 138, 4739-4756.

2337 B. Smit and T. L. M. Maesen, Molecular Simulations of Zeolites, Chem. Rev., $242008,108,4125-4184$.

2538 K. C. Park and S. K. Ihm, Comparison of Pt/zeolite catalysts for n-hexadecane 26 hydroisomerization, Appl. Catal. A, 2000, 203, 201-209.

2739 A. Gutiérrez, J. M. Arandes, P. Castaño, M. Olazar and J. Bilbao, Preliminary 28 studies on fuel production through LCO hydrocracking on noble-metal supported 29 catalysts, Fuel, 2012, 94, 504-515.

$3040 \quad$ W. M. Zhang and P. G. Smirniotis, Effect of zeolite structure and acidity on the 31 product selectivity and reaction mechanism for n-octane hydroisomerization and 32 hydrocracking, J. Catal., 1999, 182, 400-416.

3341 A. Soualah, J. L. Lemberton, L. Pinard, M. Chater, P. Magnoux and K. Mojord, 34 Hydroisomerization of long-chain n-alkanes on bifunctional Pt/zeolite catalysts, Appl. 35 Catal. A, 2008, 336, 23-28. 
142 M. A. Camblor, A. Corma, A. Martinez, V. Martinez-Soria and S. Valencia,

2 Mild hydrocracking of vacuum gasoil over NiMo-Beta zeolite catalysts, J. Catal., 1998,

3 179, 537-547.

443 N. Batalha, L. Pinard, S. Morisset, J. L. Lemberton, Y. Pouilloux, M. Guisnet, F. 5 Lemos and F. R. Ribeiro, Comparison of the performances of Pt/HBEA nano dispersed 6 over alumina and Pt/ZSM-22 catalysts in n-hexadecane hydroisomerization, React.

7 Kinet. Mech. Catal., 2012, 107, 285-294.

844 M. Y. Kim, J.-K. Kim, M.-E. Lee, S. Lee and M. Choi, Maximizing Biojet Fuel 9 Production from Triglyceride, ACS Catal., 2017, 7, 6256-6267. 45 H. Sammoury, J. Toufaily, K. Cherry, T. Hamieh, Y. Pouilloux and L. Pinard, Impact of desilication of $*$ BEA zeolites on the catalytic performance in hydroisomerization of n-C10, Appl. Catal. A, 2018, 551, 1-12.

46 W. Souverijns, J. A. Martens, G. F. Froment and P. A. Jacobs, Hydrocracking of isoheptadecanes on Pt/H-ZSM-22, J. Catal., 1998, 174, 177-184.

47 F. M. Mota, C. Bouchy, E. Guillon, A. Fecant, N. Bats and J. A. Martens, IZM2, J. Catal., 2013, 301, 20-29. Selectivity in Hydroisomerization of Hexadecane over Pt Supported on 10-Ring Zeolites: ZSM-22, ZSM-23, ZSM-35, and ZSM-48, Ind. Eng. Chem. Res., 2016, 55, 6069-6078. Valverde, Assessment of dominant factors affecting liquid phase hydroisomerization on bifunctional zeolites, Appl. Catal. A, 2008, 349, 29-39. of heptane over bimetallic bifunctional PtPd/H-beta and PtPd/USY zeolite catalysts, $J$. Catal., 1997, 165, 241-248.

A. Chica and A. Corma, Comparison of large pore zeolites for n-octane hydroisomerization: Activity, selectivity and kinetic features, Chem-Ing-Tech, 2007, 79, $29 \quad 857-870$.

3052 S. Phatanasri, P. Praserthdam, S. Kularbkeaw and S. Panichsarn, Isomerization 31 of n-Hexane Over Platinum Ion-Exchanged Zeolite Beta, React. Kinet. Catal. Lett., $32 \quad 2000,71,281-287$.

3353 B. D. Vandegehuchte, J. W. Thybaut, A. Martínez, M. A. Arribas and G. B. 34 Marin, n-Hexadecane hydrocracking Single-Event MicroKinetics on Pt/H-beta, Appl. 35 Catal. A, 2012, 441-442, 10-20. 
154 J. W. Thybaut, C. S. L. Narasimhan, J. F. Denayer, G. V. Baron, P. A. Jacobs, J.

2 A. Martens and G. B. Marin, Acid-metal balance of a hydrocracking catalyst, Ind. Eng.

3 Chem. Res., 2005, 44, 5159-5169.

455 F. Ribeiro, C. Marcilly and M. Guisnet, Hydroisomerization of n-hexane on

5 platinum zeolites, J. Catal., 1982, 78, 267-274.

656 I. Rossetti, C. Gambaro and V. Calemma, Hydrocracking of long chain linear

7 paraffins, Chem. Eng. J., 2009, 154, 295-301.

857 M. Steijns, G. F. Froment, P. A. Jacobs, J. Uytterhoeven and J. A. Weitkamp,

9 Hydroisomerization and Hydrocracking. 2. Product Distributions from n-Decane and n-

10 Dodecane, Ind. Eng. Chem. Prod. Res. Dev., 1981, 20, 654-660.

1158 J. F. M. Denayer, B. de Jonckheere, M. Hloch, G. B. Marin, G. Vanbutsele, J. A. 12 Martens and G. V. Baron, Molecular competition of C-7 and C-9 n-alkanes in vapor13 and liquid-phase hydroconversion over bifunctional Pt-USY zeolite catalysts, J. Catal., $142002,210,445-452$.

59 B. D. Vandegehuchte, J. W. Thybaut, J. A. Martens and G. B. Marin,

16 Maximizing n-alkane hydroisomerization: the interplay of phase, feed complexity and zeolite catalyst mixing, Catal. Sci. Technol., 2015, 5, 2053-2058.

60 E. Benazzi, L. Leite, N. Marchal-George, H. Toulhoat and P. Raybaud, New insights into parameters controlling the selectivity in hydrocracking reactions, J. Catal., 2003, 217, 376-387.

61 H. Toulhoat, P. Raybaud and E. Benazzi, Effect of confinement on the selectivity of hydrocracking, J. Catal., 2004, 221, 500-509. transformations using predictive materials modelling, Nat. Commun., 2015, 6:5912. Rigutto, N. Nair and T. J. H. Vlugt, Product shape selectivity of MFI-type, MEL-type, and BEA-type zeolites in the catalytic hydroconversion of heptane, J. Catal., 2017, 353, $30 \quad 54-62$.

3165 B. Huang, P. Bai, M. Neurock and R. J. Davis, Conversion of n-hexane and n32 dodecane over H-ZSM-5, H-Y and Al-MCM-41 at supercritical conditions, Appl. Catal. 33 A, 2017, 546, 149-158.

3466 C. Baerlocher, L. B. McCusker and D. H. Olson, Atlas of Zeolite Framework 35 Types, $6^{\text {th }}$ ed., 2007. 
167 J. P. Marques, I. Gener, P. Ayrault, J. M. Lopes, F. R. Ribeiro and M. Guisnet,

2 Semi-quantitative estimation by IR of framework, extraframework and defect Al species

3 of HBEA zeolites, Chem. Commun., 2004, 20, 2290-2291.

468 A. Primo and H. Garcia, Zeolites as catalysts in oil refining, Chem. Soc. Rev., $5 \quad 2014,43,7548-7561$.

669 G. Leofanti, M. Padovan, G. Tozzola and B. Venturelli, Surface area and pore

7 texture of catalysts, Catal. Today, 1998, 41, 207-219.

$870 \quad$ C. H. Bartholemew, $\mathrm{H}_{2}$ adsorption on supported noble metals and its use in

9 determining metal dispersion, in Catalysis, ed. J. J. Spivey and S. K. Agarwal, The

10 Royal Society of Chemistry, 1994, 11, pp. 93-126.

1171 J. Prasad, K. R. Murthy and P. G. Menon, Stoichiometry of Hydrogen-Oxygen

12 Titrations on Supported Platinum Catalysts, J. Catal., 1978, 52, 515-520.

72 P. S. F. Mendes, G. Lapisardi, C. Bouchy, M. Rivallan, J. M. Silva and M. F. Ribeiro, Hydrogenating activity of Pt/zeolite catalysts focusing acid support and metal dispersion influence, Appl. Catal. A, 2015, 504, 17-28. M. F. Ribeiro, Nanoscale insights into Pt-impregnated mixtures of zeolites, J. Mater.

18 Chem. A, 2017, 5, 16822-16833. flow reactor technology - A review on fast catalyst screening and kinetic studies, Catal. Today, 2000, 60, 93-109. http://www.iza-structure.org/databases/ (accessed August 26, 2018). the oil and gas industry - Monte Carlo methods, Ed. Technip, Paris, 2005. of Cyclic Alkanes by Monte Carlo Simulation New Anisotropic United Atoms Intermolecular PotentialNew Transfer Bias Method, J. Phys. Chem. B, 2002, 106, 5483-5491. Prediction of Alkenes Adsorption and Alkane/Alkene Selectivity in Silicalite, J. Phys. Chem. B, 2004, 108, 393-398. 
79 P. Ungerer, C. Beauvais, J. Delhommelle, A. Boutin, B. Rousseau and A. Fuchs, Optimization of the anisotropic united atoms intermolecular potential for $n$-alkanes, $J$. Chem. Phys., 2000, 112, 5499-5510.

80 J. F. Denayer, G. V. Baron, J. A. Martens and P. A. Jacobs, Chromatographic Study of Adsorption of n-Alkanes on Zeolites at High Temperatures, J. Phys. Chem. B, 1998, 102, 3077-3081.

81 V. Calemma, S. Peratello and C. Perego, Hydroisomerization and hydrocracking of long chain n-alkanes on Pt/amorphous $\mathrm{SiO}_{2}-\mathrm{Al}_{2} \mathrm{O}_{3}$ catalyst, Appl. Catal. A, 2000, 190, 207-218.

82 M. J. Girgis and Y. P. Tsao, Impact of catalyst metal acid balance in nhexadecane hydroisomerization and hydrocracking, Ind. Eng. Chem. Res., 1996, 35, 386-396.

83 K. J. Chao, C. C. Lin, C. H. Lin, H. C. Wu, C. W. Tseng and S. H. Chen, nHeptane hydroconversion on platinum-loaded mordenite and beta zeolites, Appl. Catal. A, 2000, 203, 211-220.

84 O. Levenspiel, Chemical Reaction Engineering, $3^{\text {rd }}$ Edition, John Wiley \& Sons, Ltd, New York, 1999.

85 D.M. Ruthven, Principles of Adsorption and Adsorption Processes, John Wiley \& Sons, New York, 1984, pp. 170-171.

86 J. F. Denayer, G. V. Baron, W. Souverijns, J. A. Martens and P. A. Jacobs, Hydrocracking of n-alkane mixtures on Pt/H-Y zeolite, Ind. Eng. Chem. Res., 1997, 36, 3242-3247.

87 J. F. Denayer, W. Souverijns, P. A. Jacobs, J. A. Martens and G. V. Baron, High-Temperature Low-Pressure Adsorption of Branched C5-C8 Alkanes on Zeolite Beta, ZSM-5, ZSM-22, Zeolite Y, and Mordenite, J. Phys. Chem. B, 1998, 102, 45884597.

88 T. J. H. Vlugt, R. Krishna and B. Smit, Molecular Simulations of Adsorption Isotherms for Linear and Branched Alkanes and Their Mixtures in Silicalite, J. Phys. Chem. B, 1999, 103, 1102-1118.

89 M. Schenk, S. L. Vidal, T. J. H. Vlugt, B. Smit and R. Krishna, Separation of Alkane Isomers by Exploiting Entropy Effects during Adsorption on Silicalite-1, Langmuir, 2001, 17, 1558-1570.

90 J. F. Denayer, A. R. Ocakoglu, B. de Jonckheere, J. A. Martens, J. W. Thybaut, G. B. Marin and G. V. Baron, Adsorption Competition Effects in Hydroconversion of Alkane Mixtures on Zeolites, Int. J. Chem. Reactor Eng., 2003, 1, A36. 
191 L. Lu, X. Lu, Y. Chen, L. Huang, Q. Shao and Q. Wang, Monte Carlo

2 simulation of adsorption of binary and quaternary alkane isomers mixtures in zeolites,

3 Fluid Phase Equilib., 2007, 259, 135-145.

492 M. A. Uguina, J. L. Sotelo, A. Rodríguez, J. I. Gómez-Cívicos and J. J. Lázaro, 5 Liquid adsorption of linear and branched paraffins onto microporous adsorbents, Sep.

6 Purif. Technol., 2006, 51, 72-79.

793 A. H. Yonli, N. Bouillault, I. Gener-Batonneau and S. Mignard, Separation of

8 Monobranched and Dibranched Isomers of n-Hexane on Zeolitic Molecular Sieves, $J$.

9 Phys. Chem. B, 2010, 114, 4465-4470.

1094 G. D. Svoboda, E. Vynckier, B. Debrabandere and G. F. Froment, Single-Event

11 Rate Parameters for Paraffin Hydrocracking on a Pt/US-Y Zeolite, Ind. Eng. Chem.

12 Res., 1995, 34, 3793-3800.

1395 T.F. Degnan and C. R. Kennedy, C.R. Impact of Catalyst Acid Metal Balance in 14 Hydroisomerization of Normal Paraffins. AIChE J., 1993, 39, 607-614.

1596 F. M. Mota, Synergetic and antagonistic effects in hydroconversion catalysts

16 composed of mixtures of solid acids, $\mathrm{PhD}$ thesis, K. U. Leuven, Belgium, 2013. 